\title{
Long-Term Pantethine Treatment Counteracts Pathologic Gene Dysregulation and Decreases Alzheimer's Disease Pathogenesis in a Transgenic Mouse Model
}

\author{
Kevin Baranger ${ }^{1}$. Manuel van Gijsel-Bonnello ${ }^{1,2} \cdot$ Delphine Stephan $^{1} \cdot$ Wassila Carpentier $^{3} \cdot$ Santiago Rivera $^{1}$. \\ Michel Khrestchatisky ${ }^{1}$ - Bouchra Gharib ${ }^{1}$ - Max De Reggi ${ }^{1}$ • Philippe Benech ${ }^{1}$
}

Published online: 2 July 2019

(C) The American Society for Experimental NeuroTherapeutics, Inc. 2019

\begin{abstract}
The low-molecular weight thiol pantethine, known as a hypolipidemic and hypocholesterolemic agent, is the major precursor of co-enzyme A. We have previously shown that pantethine treatment reduces amyloid- $\beta$ (A $\beta$ )-induced IL- $1 \beta$ release and alleviates pathological metabolic changes in primary astrocyte cultures. These properties of pantethine prompted us to investigate its potential benefits in vivo in the 5XFAD (Tg) mouse model of Alzheimer's disease (AD).1.5-month-old Tg and wild-type (WT) male mice were submitted to intraperitoneal administration of pantethine or saline control solution for 5.5 months. The effects of such treatments were investigated by performing behavioral tests and evaluating astrogliosis, microgliosis, A $\beta$ deposition, and whole genome expression arrays, using RNAs extracted from the mice hippocampi. We observed that long-term pantethine treatment significantly reduced glial reactivity and $\mathrm{A} \beta$ deposition, and abrogated behavioral alteration in $\mathrm{Tg}$ mice. Moreover, the transcriptomic profiles revealed that after pantethine treatment, the expression of genes differentially expressed in $\mathrm{Tg}$ mice, and in particular those known to be related to $\mathrm{AD}$, were significantly alleviated. Most of the genes overexpressed in $\mathrm{Tg}$ compared to WT were involved in inflammation, complement activation, and phagocytosis and were found repressed upon pantethine treatment. In contrast, pantethine restored the expression of a significant number of genes involved in the regulation of $\mathrm{A} \beta$ processing and synaptic activities, which were downregulated in Tg mice. Altogether, our data support a beneficial role for long-term pantethine treatment in preserving CNS crucial functions altered by A $\beta$ pathogenesis in Tg mice and highlight the potential efficiency of pantethine to alleviate $\mathrm{AD}$ pathology.
\end{abstract}

Key Words Alzheimer's disease $\cdot$ pantethine $\cdot$ gene expression profiles $\cdot$ neuroprotection $\cdot$ phagocytosis $\cdot 5 \mathrm{xFAD}$ mice

Max De Reggi and Philippe Benech are co-senior authors.

Philippe Benech

philippe.benech@univ-amu.fr

Kevin Baranger

kevin.baranger@univ-amu.fr

Manuel van Gijsel-Bonnello

m.vangijselbonnello@dundee.ac.uk

Delphine Stephan

delphine.stephan@univ-amu.fr

Wassila Carpentier

p3s@upmc.fr

Santiago Rivera

santiago.rivera@univ-amu.fr

Michel Khrestchatisky

michel.khrestchatisky@univ-amu.fr
Bouchra Gharib

bouchra.gharib@univ-amu.fr

Max De Reggi

max.dereggi@gmail.com

1 CNRS, INP, Inst Neurophysiopathol, Aix-Marseille Univ, Marseille, France

2 Present address: MRC Protein Phosphorylation \& Ubiquitylation Unit, Sir James Black Centre and School of Life Science - Division of Cell Signalling and Immunology, Welcome Trust Building, University of Dundee, Dundee DD1 5EH, UK

3 Sorbonne Universités, UPMC Univ Paris 06, Inserm, UMS Omique, Plateforme Post-génomique de la Pitié-Salpêtrière (P3S), F-75013 Paris, France 


\section{Background}

Alzheimer's disease (AD) is the most common cause of dementia worldwide. It is characterized by a progressive cognitive impairment thought to be associated with the accumulation of extracellular amyloid plaques, composed of amyloid- $\beta$ peptide $(A \beta)$ and intracellular neurofibrillary tangles (NFTs). NFTs result from an alteration of microtubule stabilization following the abnormal hyperphosphorylation of Tau, a microtubule-associated protein. The production of $A \beta$ is triggered by a successive proteolytic cleavage of the $\beta$-amyloid precursor protein (APP) by the $\beta$-secretase, BACE-1 (betasite APP cleaving enzyme 1 ), and the $\gamma$-secretase complex. Among the different $A \beta$ peptides generated from APP, $A \beta_{42}$ is believed to play a primary role in the development of $\mathrm{AD}$ [1]. The deposition of extracellular $A \beta$ is associated with a neuro-inflammatory response and it is suggested that upon sustained $A \beta$ production, the resulting chronic inflammation contributes to $\mathrm{AD}$ pathology $[2,3]$. Therapeutic strategies based on the reduction of Tau hyperphosphorylation or $A \beta$ are under evaluation in addition to those developed to improve cognitive function (acetylcholinesterase inhibitors) and mood disturbance or to provide neuroprotection (memantine). However, to date, available treatments show only modest symptomatic effects. Moreover, epidemiological studies have suggested that longstanding use of anti-inflammatory drugs such as NSAIDs (nonsteroidal anti-inflammatory drugs) can prevent or delay the development of $\mathrm{AD}[4,5]$. Unfortunately, treatment of $\mathrm{AD}$ patients with anti-inflammatory drugs such as celecoxib or naproxen failed to demonstrate clinical benefits $[6,7]$. These failures illustrate our poor understanding of the sequential events of neuroinflammation in $\mathrm{AD}$ that, depending possibly on timing and context, can either promote protective effects or exacerbate the disease [8]. Thus, in addition to their potential therapeutic efficacy, search for new modulators of inflammation can be useful in determining whether inflammation is a driving force or a bystander effect in AD.

Pantethine, a dietary low-molecular-weight thiol widely distributed in the living world and synthesized from pantothenic acid (vitamin B5) and cysteamine, is an intermediate in the production of co-enzyme A (CoA). This activity is thought to be related to its well-known effect on lowering cholesterol synthesis [9]. However, pantethine can be rapidly hydrolyzed in vivo to pantothenic acid and cysteamine by pantetheinase encoded by the vanin gene, and it cannot be excluded that its observed activities might result from cysteamine or pantothenic acid $[10,11]$. Pantethine elicits broad physiological activities involving multiple cellular pathways. It has been shown to exert neuroprotective effects and to reduce metabolic dysfunctions [12-14], but also to decrease inflammation and mediate immune responses $[15,16]$. We have previously shown that pantethine is able to protect mice against cerebral malaria by preserving blood-brain barrier integrity and by lowering TNF- $\alpha$ levels [16]. More recently, we demonstrated that pantethine alleviates metabolic dysfunctions and reduces astrogliosis and IL- $1 \beta$ production in primary cultured astrocytes of 5 XFAD mice [17]. Such beneficial effects were also observed in WT astrocytes treated with $A \beta$ oligomers. These data suggest that pantethine could help maintain brain homeostasis and function during $\mathrm{AD}$ pathogenesis.

Such observations prompted us to explore pantethine activity in vivo using 5XFAD mice. This animal model bears five mutations linked to familial forms of $\mathrm{AD}$ and recapitulates in a few months the main features of AD. These mutations act in an additive manner to boost the production of $A \beta$ peptides, particularly $\mathrm{A} \beta_{42}$. Though they do not present tau pathology, these mice develop cerebral amyloid plaques and gliosis as early as 2 months [18], along with increased levels of pro-inflammatory mediators $\mathrm{Il}-1 \beta$ and $C c l 2$ mRNAs [19]. Electrophysiological studies have detected hippocampal synaptic dysfunctions in 4- to 6-month-old 5XFAD animals, concomitant with memory deficits [18, 20-25]. Neuronal death, which is absent in most AD mouse models, has been described in the cortex and subiculum in 9-month-old 5XFAD mice $[18,26]$. In a previous longitudinal transcriptomic study, we showed that the main processes altered in $5 \mathrm{xFAD}$ mice, from 4 months onwards, were related to microglial activation and inflammation [27].

To investigate the effects of pantethine on AD pathology, 1.5-month-old 5XFAD transgenic (Tg thereafter) and wildtype (WT thereafter) mice were treated with pantethine for 5.5 months (see "Materials and Methods"). In line with our previous data [17], a significant decrease in gliosis and $A \beta$ plaque deposits was observed in treated $\mathrm{Tg}$ mice compared to untreated. Treatment also improved behavior with a significant decrease of aggressiveness. Transcriptomic analyses showed that pantethine was indeed able to tune down the modulations in gene expression characteristic of the Tg mice. We present for the first time an array of evidences supporting a beneficial effect of pantethine in $\mathrm{AD}$. Thus, its current use and the possibility of chronic treatment in the absence of known side effects provide the grounds to test the efficacy of pantethine in $\mathrm{AD}$ as a new therapeutic agent in preclinical and clinical studies.

\section{Materials and Methods}

\section{Chemical}

Pantethine was purchased from Sigma-Aldrich (Saint Quentin-Fallavier, France). Purity of the preparation was ascertained using high-performance liquid chromatographycoupled mass spectrometry (HPLC-LC-UV-MSD) and the purity of the compound reached $99 \%$. Sodium chloride $(\mathrm{NaCl})$ 
and phosphate-buffered saline (PBS) were purchased from Euromedex (Souffelweyersheim, France). Proteinase inhibitors cocktail was from Millipore (Molsheim, France). All the chemical powders were of analytical grade and purchased from Sigma-Aldrich.

\section{Animals and Pantethine Treatment}

We used 5XFAD male transgenic mice, which overexpress two human transgenes bearing five mutations linked to familial AD: App (Swedish mutation K670N, M671L; Florida mutation I716V; London mutation V717I) and Psen1 (M146L; L286V), under transcriptional control of the mouse Thy1 promoter. These mice exhibit AD-related symptoms earlier than other AD animal models and amyloid deposition starts in the cortex and subiculum at 2 months of age [18]. Heterozygous male 5XFAD transgenic animals (B6/SJL background) and WT controls were obtained after breeding in our animal house facility $[19,27,28]$.

Animals were housed in cages in a controlled environment $\left(22-25^{\circ} \mathrm{C}, 50 \%\right.$ humidity, and a 12 -h light/dark cycle) with free access to standard laboratory diet and water. At 1.5 month, Tg and WT mice were each separated into treated and vehicle groups ( $n=10$ per group). Based on a previous study [13], Tg and WT treated mice were given each an intraperitoneal injection of $15 \mathrm{mg}$ of pantethine diluted in saline, three times a week for 5.5 months; vehicle animals received saline injections as control. At the age of 7 months, the animals were submitted to the intrudal aggressivity test (see below) and then sacrificed. Mice were anesthetized with pentobarbital $(0.36 \mathrm{~g}$ per $\mathrm{kg})$ and transcardially perfused with $50 \mathrm{ml}$ of $\mathrm{NaCl} 0.9 \%$. Brains were microdissected and hippocampi collected for the assays. All experimental procedures were approved by the Ethics Committee of the Medical Faculty of Marseille and were carried out in accordance with the guidelines published in the European Communities Council Directive of November 24, 1986 (86/609/EEC). All efforts were made to reduce animal suffering and the number of mice.

\section{Total RNA Isolation and Extraction}

Hippocampi from each experimental group ( $n=3$ per group) were quickly snap-frozen in liquid nitrogen and stored at $80{ }^{\circ} \mathrm{C}$ until use. Total RNA was extracted using the RNeasy Mini kit (Qiagen, Courtaboeuf, France) according to the manufacturer's instruction. RNA concentration was determined using a nanodrop 2000 spectrophotometer (ThermoFisher Scientific, Villebon sur Yvette, France) and RNA integrity assessed on an Agilent 2100 Bioanalyzer (Agilent Technologies, Les Ulis, France).

\section{Microarray Assay}

The microarray assay included four different experimental conditions: hippocampi from WT and Tg mice vehicle or treated with pantethine ( $n=3$ per group). A total of 12 biological samples were therefore processed for the microarray experiment. The mouse WG-6 expression BeadChip (Illumina Inc., Cambridge, UK), comprising 47,232 transcripts was used to generate gene expression profiles and hybridized to cRNAs, which were synthesized, amplified, and purified using the Illumina TotalPrep RNA Amplification Kit (Ambion, Foster City, CA, USA) following the manufacturer's recommendations. Briefly, 200 ng of RNA was reverse transcribed. After second strand synthesis, the cDNA was transcribed in vitro and cRNA labeled with biotin-16-UTP. Labeled probe hybridization to the Beadchips was carried out using Illumina's protocol. The Beadchips were scanned on the Illumina IScan using Illumina IScan image data acquisition software. Illumina GenomeStudio software and LumiR (www.bioconductor.org) were used for preliminary data analysis, data normalization, and quality controls. Microarray statistical analyses were performed using the Biometric Research Branch array tools (http://inus.nci.nih. gov/BRB-Array Tools.html) and the Multi Experiment Viewer software (MeV4.0; [29]). Expression values were filtered for a $p$ value $\leq 0.05$. Functional analysis was performed using the text-mining-based software, PredictSearch [27]. Microarray data are available in the Array Express database [www.ebi.ac.uk/arrayexpress] under accession number E-MTAB-6772.

\section{Real-Time Quantitative PCR}

Following microarray analysis, the expression levels of some selected genes were further validated using quantitative PCR (qPCR) technique. Total RNA samples $(1 \mu \mathrm{g})$ extracted from the hippocampi of all animals $(n=3)$ in each group were subjected to reverse-transcription reactions to synthesize cDNA using oligodT, RNase-out, and M-MLV RT enzyme (ThermoFisher Scientific) according to the manufacturer's instructions. Two genes, Gfap and Aifl, related to astrocytic and microglial activation, respectively, were selected for prevalidation of samples, and one housekeeping gene, Gapdh, was used for sample normalization. Real-time qPCR experiments were carried out with the 7500 Fast Real-Time PCR system (Applied Biosystems, Thermo Fisher Scientific), using TaqMan Fast Universal PCR Laster Mix (2X) and the following TaqMan Gene Expression probes were used: Gfap, Mm01253033_m1; Aif1, Mm00479862_g1; Il-1 $\beta$, Mm01336199_m1; Csf1r, Mm01266652_m1; Tlr2, Mm01213946_g1; Cyba, Mm00514478_m1; Tnf- $\alpha$, Mm00443258_m1 and Gapdh, Mm99999915_g1. We used $7.5 \mathrm{ng}$ of previously prepared cDNA and samples were run 
in triplicate. Relative expression levels were determined according to the $\Delta \Delta \mathrm{Ct}$ method in which the expression level of the mRNA of interest is given by $2^{-\Delta \Delta C T}$ in which $\Delta \Delta \mathrm{CT}=\Delta \mathrm{CT}$ target $\mathrm{mRNA}-\Delta \mathrm{CT}$ reference mRNA (Gapdh) in the same sample [19].

\section{ELISA Assay}

The cortices of mice brains ( $n=3$ for each condition) were homogenized in $100 \mathrm{mM}$ PBS containing $2 \mathrm{mM} \mathrm{NaF}$, $2.5 \mathrm{mM} \mathrm{Na}_{4} \mathrm{P}_{2} \mathrm{O}_{7}, 1 \mathrm{mM} \mathrm{Na} \mathrm{VO}_{4}, 1 \%$ Triton X-100, pH 7.2, supplemented with $1 \%$ protease inhibitor cocktail and centrifuged at $12,000 \times \mathrm{g}$ for $20 \mathrm{~min}$ at $4{ }^{\circ} \mathrm{C}$. Protein concentration was quantified by using the Bio-Rad DC ${ }^{\mathrm{TM}}$ protein assay kit following the manufacturer's instructions (Bio-Rad, Marnes-La-Coquette, France). The levels of IL-1 $\beta$ were analyzed by ELISA assay (Peprotech, Neuilly-sur-Seine, France) according to the manufacturer's instructions.

\section{Immunostaining, Image Analysis, and Quantification}

Anesthetized mice were transcardially perfused with $50 \mathrm{ml}$ of $\mathrm{NaCl} 0.9 \%$, followed by $50 \mathrm{ml}$ of AntigenFix solution (Diapath, MM France, Brignais, France). Coronal sections of $30 \mu \mathrm{m}$ were obtained using a vibratome (Microm HM650V, Thermo Fisher Scientific) and stored at $-20^{\circ} \mathrm{C}$ in cryoprotectant containing $30 \%$ glycerol, $30 \%$ ethylene glycol, and $40 \%$ in phosphate buffer $0.5 \mathrm{M}, \mathrm{pH} 7.4$. Free-floating sections were first permeabilized and blocked for $1 \mathrm{~h}$ at room temperature using a solution of PBS $1 \mathrm{X}, 0.1 \%$ Triton $\mathrm{X}-100$, and $3 \%$ BSA. Sections were then incubated overnight at $4{ }^{\circ} \mathrm{C}$ with primary antibodies: mouse monoclonal anti-A $\beta 6 \mathrm{E} 10$ (1/300; Covance, Ozyme, Saint-Quentin en Yvelines, France), rabbit polyclonal anti-IBA1 (1/300; Wako, Sobioda, Montbonnot, France), and rabbit polyclonal anti-GFAP (1/300, Dakocytomation, France) followed by an incubation with appropriate secondary antibodies: AlexaFluor@488-goat anti-rabbit (1/800) or AlexaFluor@568-goat anti-mouse (1/800) (Thermo Fisher Scientific) for $1 \mathrm{~h}$ at room temperature. Nuclei were stained with Hoechst $(0.5 \mu \mathrm{g} / \mathrm{mL}$, Thermo Fisher Scientific). Omission of the primary antibody was used as control. Sections were mounted using Prolong Gold Antifading reagent on Superfrost glass slides (Thermo Fisher Scientific). Images were taken and processed using a confocal microscope (LSM700) and Zen software (Zeiss, Jena, Germany), as previously described [24, 30]. Densitometric analysis of immunostained sections was performed using ImageJ software on 3 hippocampal sections from 3 animals for each experimental group. The area of $\mathrm{GFAP}^{+}$astrocytes and IBA $1^{+}$microglia was determined. The same threshold of fluorescence was applied across the experimental groups and data were normalized to the values in the WT group. Extracellular amyloid deposits were blindly scored in the three brain sections per animal and expressed as number of plaques per $\mathrm{mm}^{2}$ of brain surface.

\section{Intrudal Aggressivity Test}

The effect of pantethine on Tg male mice aggressiveness was evaluated with the resident-intruder paradigm according to a previously published method [31] and modified according to our experimental situation. The animals to be tested, treated or not with pantethine ( $n=10$ per group) were maintained in their individual resident cage in order to mimic the natural pattern of wild animals that defend their territory. The intruders were WT male mice $(n=10)$ from the same genetic background, but not included in this protocol. For the test, a WT animal was introduced in the cage of a $\mathrm{Tg}$ and their behavior were monitored with a video camera for $180 \mathrm{~s}$. The following behavioral elements were scored: 1) latency: the time between the introduction of the intruder and the first threat or attack; 2) number of threats that are generally in the form of frenetic tail agitation; 3) number of assaults. Threats and assaults were exclusively facts of the Tg resident as the WT intruder always behaved passively. In the case of violent assault, the animals were immediately separated and the test ended. The offense intensity was estimated on a scale of 0 to 5 . The latency time was set at $180 \mathrm{~s}$ when no reaction, threat, or attack was noticed. The tests were done 3 times on 3 consecutive days under normal light, starting at $10 \mathrm{am}$. From one test to another, the intruders were circularly permuted. Intrudal aggressivity experiments were performed at least 3 times for each animal.

\section{Statistical Analysis}

All the data were analyzed with Kaleida Graph or Prism softwares and the values represent the means \pm SEM of the indicated number of independent experiments/animals. ANOVA followed by a Fisher's LSD post hoc test was used for multiple comparisons. For the aggressiveness analysis, we used a nonparametric Mann-Whitney test and results are represented as median and interquartile range. Only $p$ values less than 0.05 were considered significant. The $p$ levels $p<0.05, p<0.01$, and $p<0.001$ are denoted with asterisks $*$, **, and ***, respectively.

\section{Results}

\section{Pantethine Reduces Gliosis and Amyloid Plaque Number}

The 5XFAD mouse model of AD is characterized by an increase in glial reactivity and amyloid plaque number as 
aging progresses. At first, immunohistological analyses of brain sections at the hippocampal level in 7-month-old Tg and WT mice (Fig. 1A) supported our previous results on cultured astrocytes [17]. Indeed, in sections immunostained with anti-GFAP and anti-IBA1 antibodies, Tg mice consistently exhibited a higher signal (10-fold and 20-fold increase, respectively) than WT mice (Fig. 1A, B). Pantethine treatment reduced this signal significantly in Tg animals, with an $80 \%$ and $40 \%$ reduction for GFAP and IBA1, respectively. Interestingly, pantethine reduced GFAP staining nearly to WT levels (Fig. 1B). Similarly, staining with $A \beta$-specific antibodies showed that the numerous amyloid deposits observed in Tg mice were dramatically reduced by $85 \%$ upon pantethine treatment (Fig. 1C). These results indicated that pantethine was able to reduce significantly glial reactivity as well as the number of amyloid plaques in $\mathrm{Tg}$ mice.

\section{Pantethine Reduces 5XFAD Aggressive Behavior}

AD pathology leads to cognitive impairment and behavioral alterations linked to amyloid-mediated neuroinflammation and neurodegeneration. Although altered cognition has been well characterized in a variety of transgenic models, it has been reported that disturbance in hippocampal learning performance can be detected using the Morris water maze (MWM) in male 5XFAD not before 6 to 9 months of age [23, 32]. Alternatively, social withdrawal and aggressiveness have been clearly documented not only in $\mathrm{AD}$ patients [33-35], but also in different AD mouse models [34, 36-38], and was proposed to be useful in screening putative drug treatments for AD [36]. For these reasons, we chose to evaluate the potential benefit of pantethine on the behavior of 7-month-old AD mice rather than on cognitive performances. Thus, we performed an
Fig. 1 Effects of pantethine on astroglia and microglia reactivity in WT and Tg mice. (A) Representative epifluorescence microphotographs showing changes in astroglia and microglia reactivity with GFAP and Ibal immunostaining, respectively, and amyloid plaques (anti-A $\beta$ 6E10 immunostaining) in the hippocampus (Hc) of untreated or pantethine-treated WT and Tg animals, counterstained with nuclear marker Hoechst (blue). Scale bar $100 \mu \mathrm{M}$. Quantification of changes (B) in GFAP, IBA1 immunostaining and $(C)$ number of $\mathrm{A} \beta$ plaques measured as the immunostained area/total area of the hippocampus. Values are the mean \pm SEM of three brains ( 3 slices/brain) per group. ${ }^{*} p<0.05$; $* * p<0.01 ; * * * p<0.005$ when comparing $\mathrm{WT}+\mathrm{P}, \mathrm{Tg}$ and $\mathrm{Tg}+$ $P$ groups vs WT, ANOVA

followed by post hoc Fisher LSD test for (B) and Student's $t$ test for (C) a
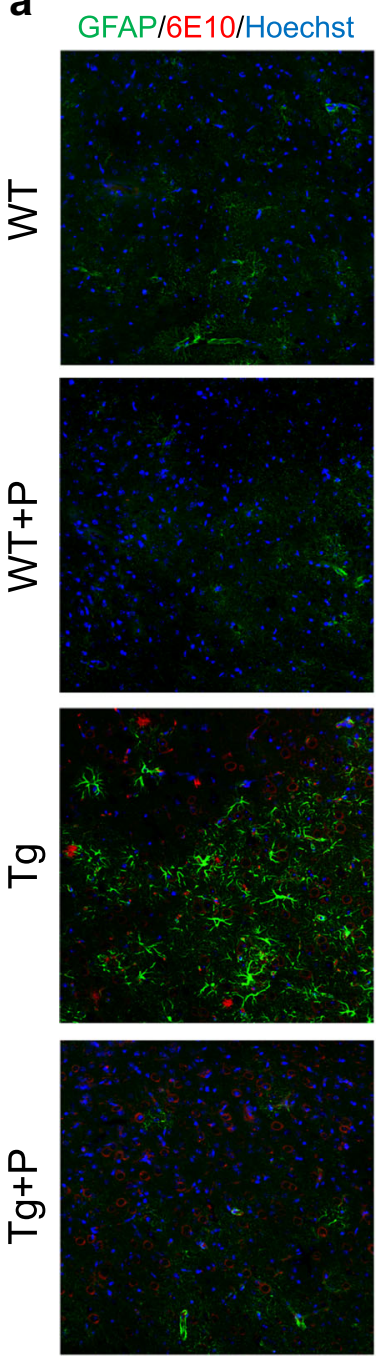

b
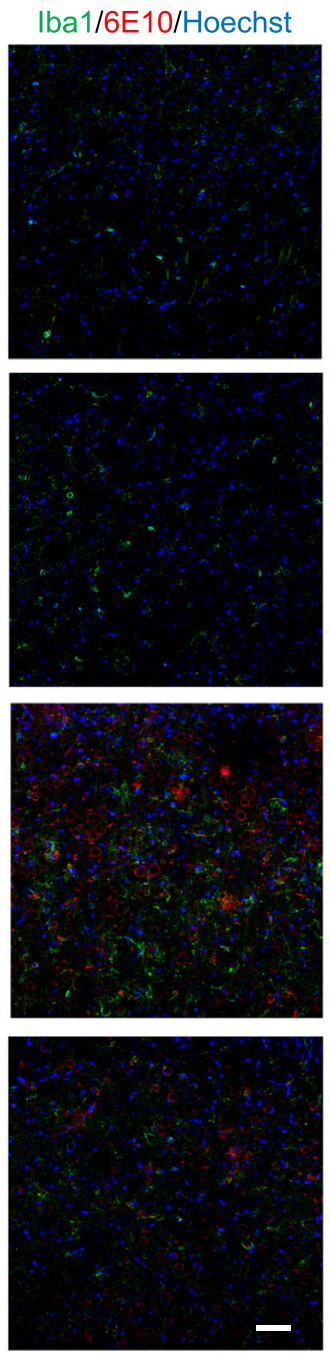

C
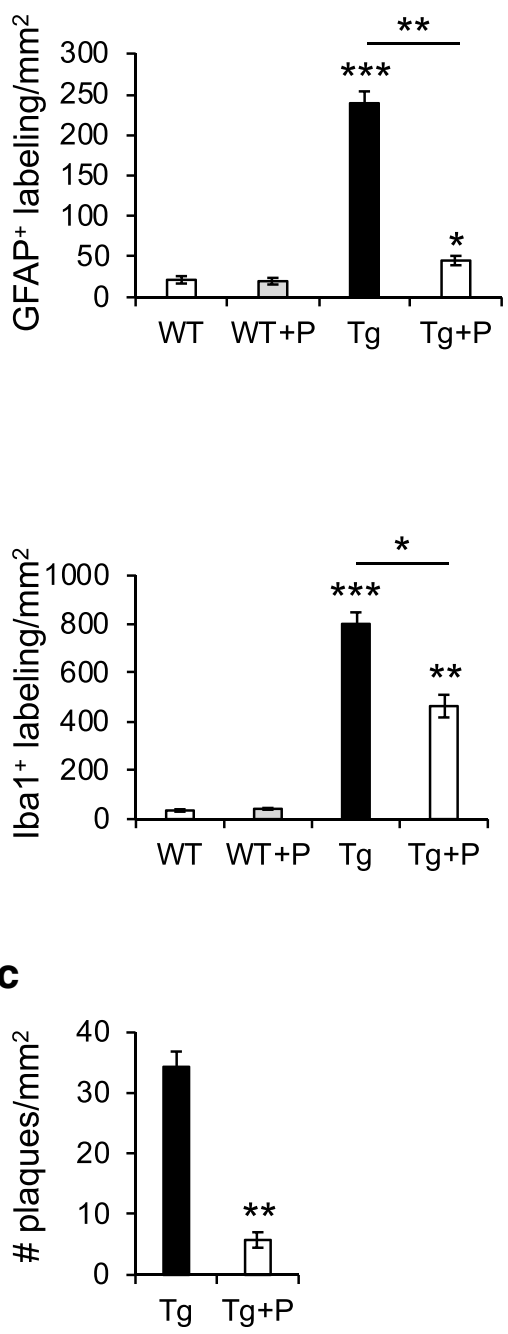
intrudal aggressive test with treated and untreated Tg mice in the presence of WT animals. When comparing untreated and treated 5XFAD mice (Fig. 2), we observed a significant difference between these two groups, not only in offense intensity (Fig. 2A), but also in attack latency (Fig. 2B). Most (8 out of 10) vehicle-treated Tg animals react aggressively to the presence of WT mice, although only 4 out of 10 treated animals exhibit such a behavior (Fig. 2A). Moreover, pantethine-treated animals present a longer latency period (150 s) between the attacks (Fig. 2B), confirming that pantethine treatment is able to modulate the aggressive attitude of $\mathrm{Tg}$ mice.
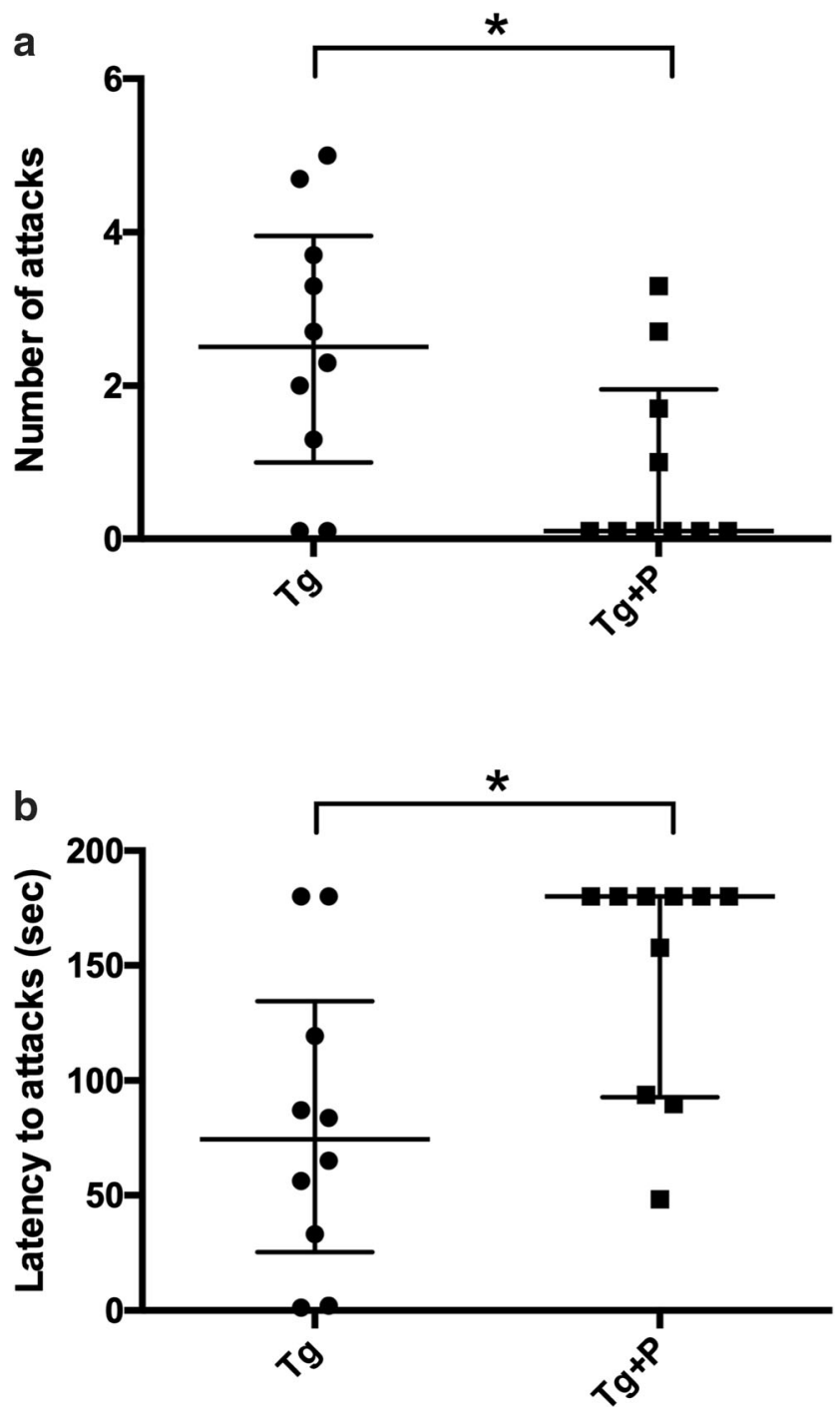

Fig. 2 Effects of pantethine on the aggressive behavior of 5XFAD mice. Quantification of the number of attacks (A) and latency to attacks (B) of untreated $(\mathrm{Tg}$, black circles) and pantethine-treated $(\mathrm{Tg}+\mathrm{P}$, black squares) Tg mice towards WT male mice intruders. Values of ten animals are represented as median with interquartile range (done in triplicate with a different intruder as described in the "Materials and Methods"). $* p<0.05$, Mann-Whitney test

\section{Panthetine Moderates the Dysregulation of Gene Expression Observed in 5XFAD Mice}

cDNA microarrays were performed to investigate whether the reduced astroglial and microglial activation, as well as the positive impact on behavior observed after pantethine treatment, could be related to a modulation of the expression of genes involved in these processes. The selection of genes in $\mathrm{Tg}$ animals presenting a reduced expression upon pantethine treatment (filtered for a threshold $\leq 0.6$ ) led to the identification of 47 specific genes (Fig. 3, left panel). Interestingly, $91 \%$ of these genes (gene set 1) were expressed at higher levels in Tg mice compared to WT. Similarly, $89 \%$ of the top 47 genes (gene set 2) upregulated in pantethine-treated $\mathrm{Tg}$ animals when compared to untreated $\mathrm{Tg}$ mice (filtered for a threshold $\geq 1.5$ ) were downregulated in Tg when compared to WT (Fig. 3 , right panel). Noteworthy, pantethine had very little if no effect at all on the expression of most of these genes in WT animals (Fig. 3). It must be noted that none of the genes encoding proteins directly associated with the APP/A $\beta$ metabolism (e.g., Bace-1, App, or $\gamma$-secretase members) were modulated between vehicle and pantethine-treated $\mathrm{Tg}$ mice (data not shown).

A similar tendency was confirmed when we analyzed the genes modulated in $\mathrm{Tg}$ mice after pantethine treatment in relation to all genes differentially expressed in Tg compared to WT (Fig. 4). Among the 154 genes downregulated in Tg, 80\% (124 genes) were upregulated by pantethine in Tg although none were further repressed. On the other hand, out of the 362 genes whose expression was upregulated in Tg versus WT, only 43 genes (12\%) showed a reduced expression upon pantethine treatment (Fig. 4). These observations suggested that pantethine was able to counteract the modulation of gene expression in 5XFAD mice and this inhibitory effect could account for the preservation by pantethine of physiological functions normally altered in these mice.

\section{Inhibitory Effect of Pantethine on the Expression of 5XFAD Dysregulated Genes in Inflammation and Related Activities}

At first, to investigate which processes could be targeted by pantethine, we focused our analysis on genes whose upregulation was statistically significant in Tg compared to WT and that presented a lower expression in pantethine-treated $\mathrm{Tg}$ animals. A significant number of these genes (Table 1) were reported in our previous temporal gene profiling study [27] and are known to be related to glial activation and neuroinflammation in an $\mathrm{AD}$ context. Figure 5 shows the relationships between these genes and related AD activities identified through a bibliographic search using PredictSearch software $[27,39]$. Indeed, most of these activities highlight the role of the selected genes in astroglial activation (Gfap, S100a6), 
Fig. 3 Effects of pantethine on genes differentially expressed in $\mathrm{Tg}$ and WT mice. Expression values were filtered for $p$ values $<$ 0.05 as provided by Illumina technology. Fold changes were deduced from the ratios $(\mathrm{Tg}+\mathrm{P} /$ Tg, Tg/WT, WT + P/WT) between the four different groups and means were calculated. Selecting a fold change $\leq 0.6$ leads to 47 genes repressed by pantethine (gene set 1 in left panel). A similar number of the top pantethine-induced genes (gene set 2 in right panel) selected for a fold change $\geq 1.5$ is displayed. All the repressed or induced fold changes values are colored in white or in dark gray, respectively, although unmodulated genes are indicated in light gray

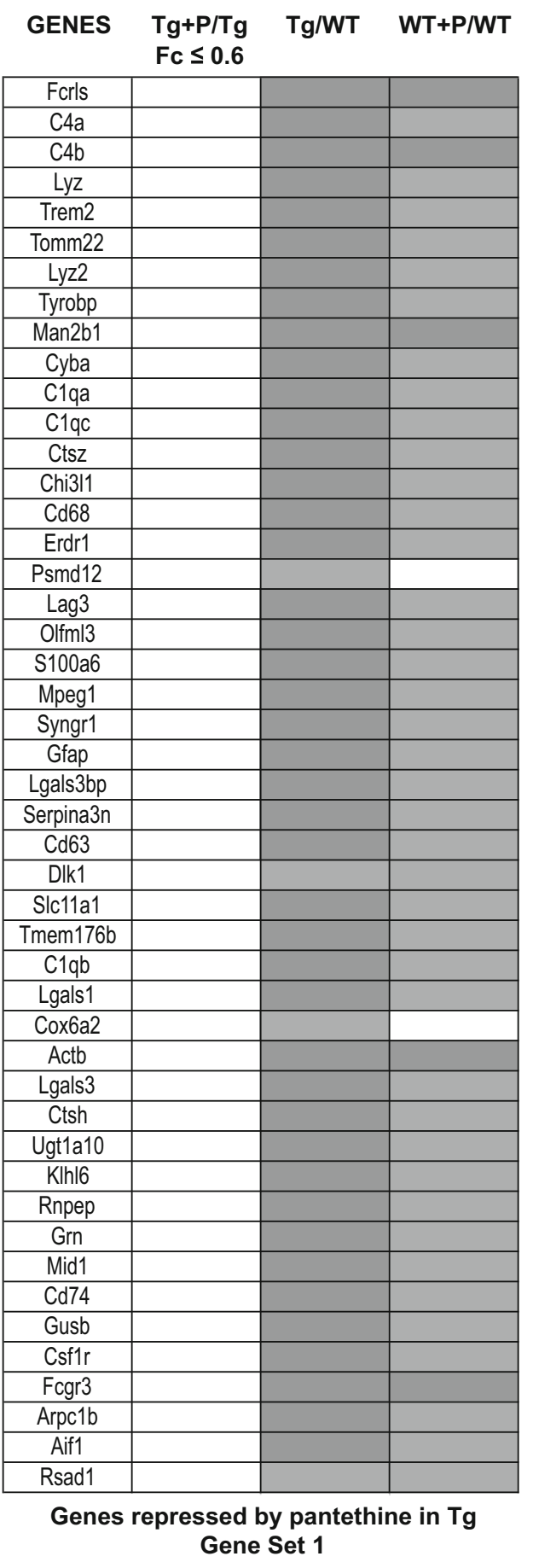

\section{GENES Tg+P/Tg Tg/WT WT+P/WT $\mathrm{Fc} \geq 1.5$}

\begin{tabular}{|c|l|l|l|}
\hline Thsd4 & & & \\
\hline Grm5 & & & \\
\hline Zbtb7a & & & \\
\hline Cplx2 & & & \\
\hline Pja2 & & & \\
\hline Syn2 & & & \\
\hline Zfp365 & & & \\
\hline Slc4a7 & & & \\
\hline Mtap1b & & & \\
\hline Zeb2 & & & \\
\hline Scn1a & & & \\
\hline Iqgap2 & & & \\
\hline Atxn1 & & & \\
\hline Cap1 & & & \\
\hline G3bp2 & & & \\
\hline Skiv212 & & & \\
\hline Rgs7bp & & & \\
\hline Nipbl & & & \\
\hline KIf7 & & & \\
\hline Ankrd11 & & & \\
\hline Ddx24 & & & \\
\hline Gcap14 & & & \\
\hline Syt1 & & & \\
\hline Pcdha7 & & & \\
\hline Klf6 & & & \\
\hline Klf9 & & & \\
\hline Pde1a & & & \\
\hline Kalrn & & & \\
\hline Rnf182 & & & \\
\hline KIf13 & & & \\
\hline Susd4 & & & \\
\hline Cacna2d1 & & & \\
\hline Purb & & & \\
\hline Pcdh17 & & & \\
\hline Irs2 & & & \\
\hline Ppap2b & & & \\
\hline Mllt4 & & & \\
\hline Mfhas1 & & & \\
\hline Pdpk1 & & & \\
\hline Cnot4 & & & \\
\hline Fam168a & & & \\
\hline Glg1 & & & \\
\hline Ankrd12 & & & \\
\hline Rusc2 & & & \\
\hline Pkp4 & & & \\
\hline Odz4 & & & \\
\hline Kif3a & & & \\
\hline Genes inducel & \\
\hline
\end{tabular}

Genes induced by pantethine in $\mathrm{Tg}$ Gene Set 2 microglial activation (Aif1/Ibal, CD68, Hexb2), and phagocytosis (Cd14, Trem2, Tyrobp, Csf1r, Clqa, Clqb, Clqc, C4a, and $C 4 b)$.

Similarly to allograft inflammatory factor 1/Ibal (AIF1), CD68 is considered a marker of phagocytic microglia. Cd63, encoding a marker of exosomes, and Lgals3 (galectin 3), were found to be co-expressed in $5 \mathrm{XFAD}$ mice in $\mathrm{A} \beta$ plaqueassociated microglia [40], cells that are considered as primary contributors to neuroinflammation in $\mathrm{AD}$ pathology.
Furthermore, the reduced expression of Gfap, a marker of astroglial activation, suggested that the effects of pantethine were not restricted to microglia. Indeed, S100a6, that encodes $\mathrm{a} \mathrm{Ca}^{2+} / \mathrm{Zn}^{2+}$ binding protein, was reported to be overexpressed in astrocytes of $\mathrm{AD}$ patients and $\mathrm{AD}$ mouse models [41]. In contrast to astrocytes of white matter in which all S100A6 proteins were expressed homogeneously, almost all S100A6 immunoreactive cells within the gray matter were concentrated in astrocytes surrounding the $A \beta$ deposits. 


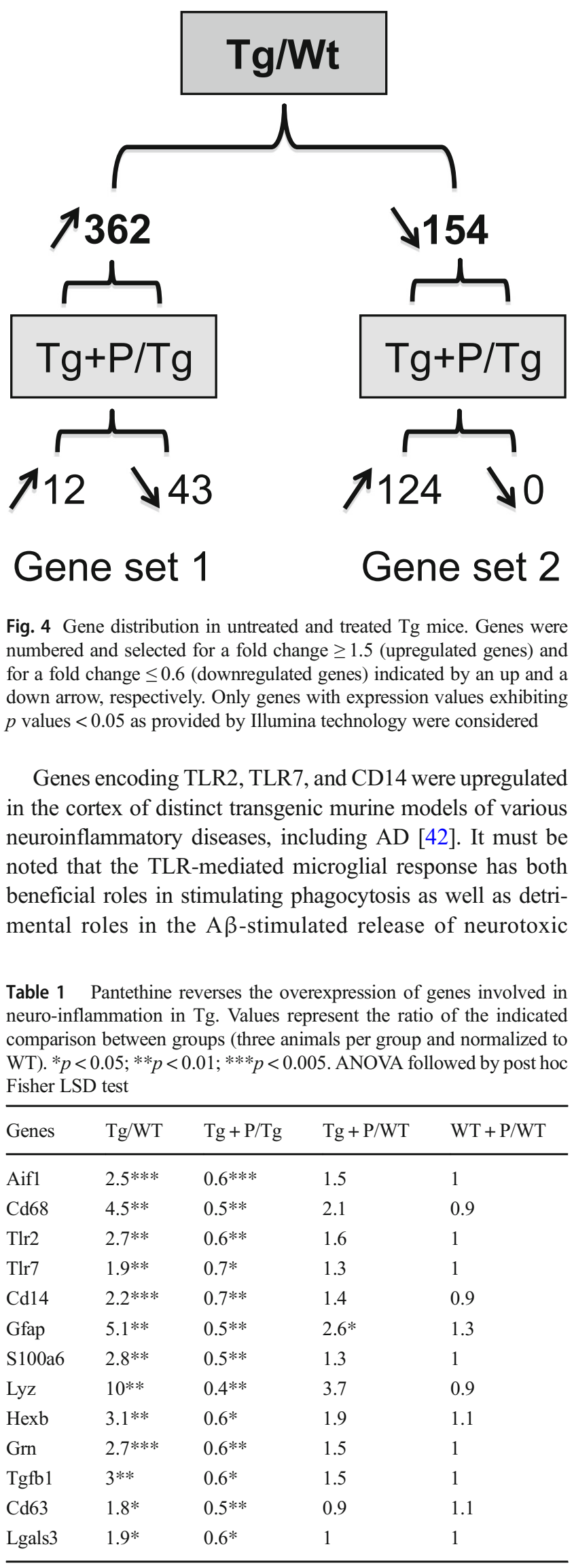

products [43]. TLR2 is a known primary receptor for $A \beta$ peptide to trigger neuroinflammation $[44,45]$. Its co-receptor, $\mathrm{CD} 14$, is a critical regulator of the microglial inflammatory response that modulates $A \beta$ deposition [46].

In addition to other inflammatory markers, complement activation products are known to be markedly upregulated in $\mathrm{AD}$ brains in response to soluble and insoluble amyloid peptides $[47,48]$. Their activation, detected at the early stages of amyloid deposition, coincides with the clinical expression of $\mathrm{AD}[49,50]$. The encoded products are components of both the alternative phagocytic pathway (AP), triggered by bacterial membranes, and the classical phagocytic pathway (CP), initiated when $\mathrm{C} 1 \mathrm{Q}$ binds to immune complexes $[48,51,52]$. The expression of these components in transgenic mice might also be considered as part of a protective response. For instance, C1Q was shown to protect cultured primary neurons against $\mathrm{A} \beta$ [53], and $\mathrm{C} 3$ deficiency in $\mathrm{AD}$ transgenic mice was reported to elicit an acceleration of plaque deposition and neurodegeneration compared to WT [54].

Other genes revealed by our analyses such as Csf1r, Trem2, and Tyrobp (Table 2) have been reported to be involved in phagocytosis (Fig. 5). In addition to the classical phagocytic receptors FCGR3 and CD68, CSF1R (colony stimulating factor 1 receptor) as well as $\mathrm{CD} 14$, contribute to $\mathrm{A} \beta$ phagocytosis $[55,56]$. In a recent report [57], the role of CSF1R was determined as being crucial for the accumulation of intraneuronal amyloid peptides and the consequent formation of neuritic plaques. Here, we confirmed that the expression of Csflr was increased in Tg compared to WT and significantly decreased upon pantethine treatment (Table 2). Furthermore, pantethine reduced the expression of Trem 2 , which presented the highest fold change (10-fold) within the set of $\mathrm{Tg}$ overexpressed genes (Table 1), along with the gene encoding its interactor, Tyrobp. Trem 2 is highly expressed in microglia and the Trem2/Tyrobp pathway activates phagocytosis of apoptotic neurons as well as $A \beta$ in cultured cells [58]. Although this pathway inhibits TLR-induced inflammation [59], it was reported that, in a mouse model of $\mathrm{AD}$, Trem 2 deficiency reduced pro-inflammatory cytokines (IL-1 $\beta$ and IL-6) as well as astrogliosis [60]. According to this observation, in $\mathrm{AD}$ mice, the reduced expression of Trem 2 in response to pantethine at a particular inflammatory stage might contribute to hamper the production of cytokines in Trem 2 expressing cells.

AIF1 binds to and polymerizes F-actin, and regulates RAC1 activity [61]. RAC1 participates in the activation of the NADPH oxidase (NOX) complex leading to production of superoxide (Fig. 5). Among the genes encoding the different subunits of this complex, only the overexpression of $C y b a$ in $\mathrm{Tg}$ (cytochrome b-245 alpha gene/p22phox) was drastically reduced in pantethine-treated Tg as shown in Table 1. CYBA is considered as a critical component of the membrane-bound oxidase of phagocytes that generates superoxide. $A \beta$ is 


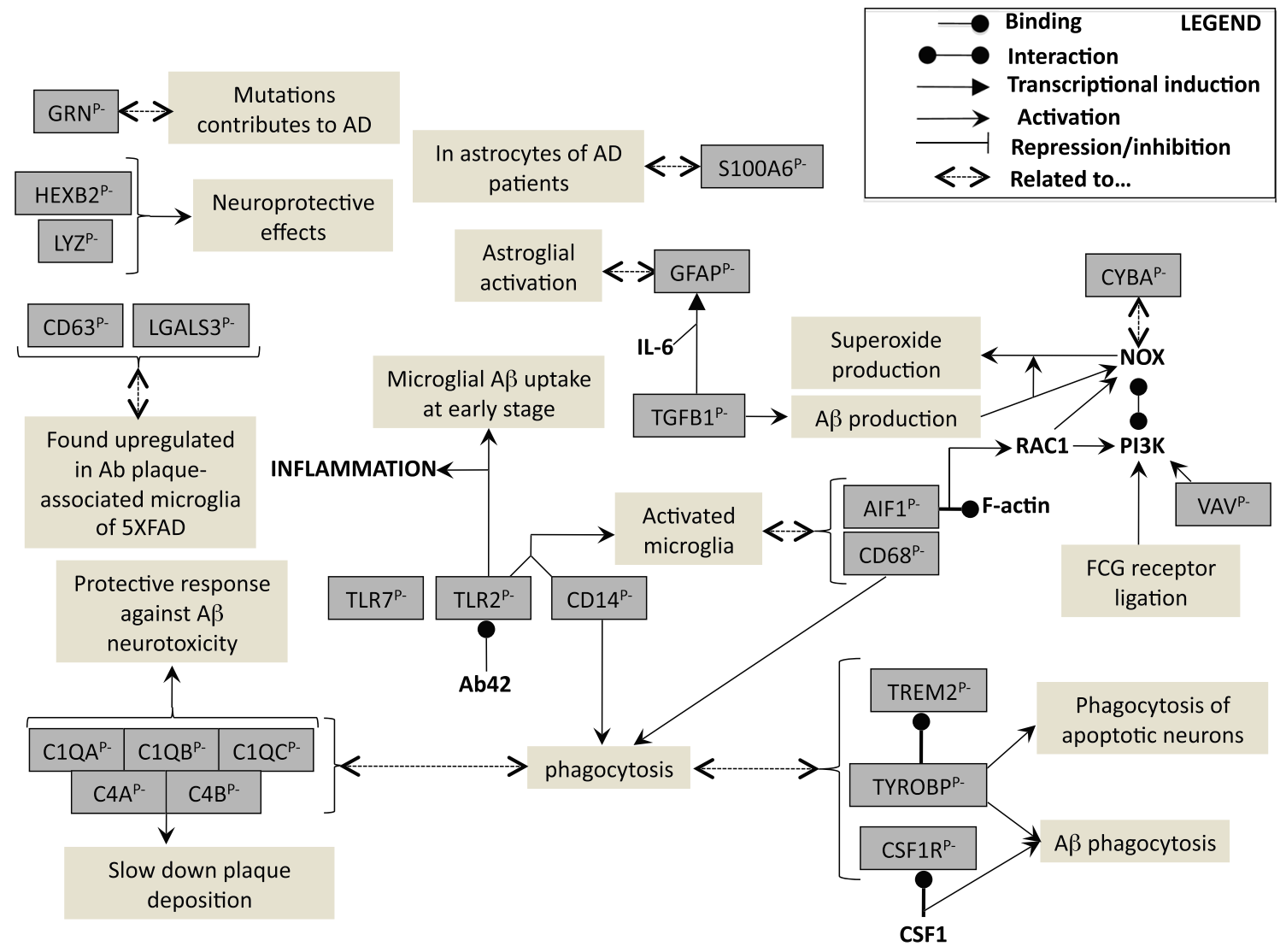

Fig. 5 Schematic representation of functional networks involving genes whose overexpression in $\mathrm{Tg}$ was repressed by pantethine. Table of legends is provided (at the top right of the figure). Modulated genes are within a gray box and reduced expression by pantethine is indicated by $\mathrm{P}-$ in superscript

known to act on NOX in both hippocampal microglial and astrocyte cells to produce neurotoxic superoxide [62, 63], through the interaction of the NOX complex with phosphatidylinositol-3-phosphate (PI3P). Production of PI3P requires activation of $\mathrm{RAC} 2$, a member of the Ras superfamily

Table 2 Pantethine reverses the overexpression of genes involved in phagocytosis in $\mathrm{Tg}$. Values represent the ratio of the indicated comparison between groups (three animals per group and normalized to WT). $* p<0.05 ; * * p<0.01 ; * * * p<0.005$. ANOVA followed by post hoc Fisher LSD test

\begin{tabular}{|c|c|c|c|c|}
\hline Genes & $\mathrm{Tg} / \mathrm{WT}$ & $\mathrm{Tg}+\mathrm{P} / \mathrm{Tg}$ & $\mathrm{Tg}+\mathrm{P} / \mathrm{WT}$ & $\mathrm{WT}+\mathrm{P} / \mathrm{WT}$ \\
\hline C1qa & $4.8^{*}$ & $0.5^{*}$ & 1.8 & 1 \\
\hline $\mathrm{C} 1 \mathrm{qb}$ & $4.2 * *$ & $0.5^{*}$ & 2.2 & 1 \\
\hline $\mathrm{Clqc}$ & $4.6^{* *}$ & $0.5^{*}$ & 1.9 & 1 \\
\hline $\mathrm{C} 4 \mathrm{a}$ & $6.8 * * *$ & $0.3 * * *$ & 2.2 & 1.3 \\
\hline $\mathrm{C} 4 \mathrm{~b}$ & $8.1 * * *$ & $0.3 * * *$ & 2.8 & 1.5 \\
\hline Csflr & $2.7 * * *$ & $0.6^{* *}$ & $1.5^{*}$ & 1.1 \\
\hline Trem2 & $9.5 * * *$ & $0.4 * * *$ & 3.4 & 1.2 \\
\hline Tyrobp & $6 * * *$ & $0.4 * * *$ & $2.5^{*}$ & 1 \\
\hline Cyba & $3.9 * * *$ & $0.5 * * *$ & 1.7 & 0.9 \\
\hline Vav1 & $2.4 * * * *$ & $0.7 * *$ & $1.6^{*}$ & 1.1 \\
\hline
\end{tabular}

of small guanosine triphosphate (GTP)-metabolizing proteins, VAV (vav guanine exchange factor) and FCG receptor ligation [64]. Among these factors, Tg overexpression of Vav1 was indeed lowered by pantethine (Table 1). Thus, the inhibitory effect of pantethine on the upregulation of $C y b a$, and Vavl genes in transgenic mice supported a reduced activity of the NOX complex and therefore an ongoing decreased production of superoxide.

On the other hand, we found that some of the genes upregulated in Tg and lowered by pantethine (Table 1) are known to be involved in neuroprotection, such as $L y z$ and Hexb2 (Fig. 5). For instance, rescuing Hexb expression in $\mathrm{Hexb}^{-/-}$mice, which was detected exclusively in microglia [65], reduces neuroinflammation and can attenuate behavioral deficits [66].

As previously reported [27], we also observed an increased expression of Grn (granulin) in Tg that was reduced by pantethine (Table 1). GRNs are a family of secreted peptides generated by proteolytic release from progranulin. Interestingly, mutations in the Grn gene cause frontotemporal lobar degeneration and may contribute to $\mathrm{AD}$ [67].

Regarding genes of the TGF family, such as Tgfbl and $T g f b r 2$, studies in transgenic animal models suggest that TGF- $\beta$ might primarily contribute to AD pathogenesis by influencing $A \beta$ production and deposition, resulting in brain 
microvasculature damage [68]. Moreover, TGF- $\beta$ was shown to act in synergy with IL-6 to turn on the expression of Gfap [69]. In contrast, several studies report evidence for neuroprotective features of TGF- $\beta 1[70,71]$. Indeed, it was reported that reduced TGF- $\beta$ signaling leads to neurodegeneration and results in increased levels of secreted $A \beta$ [72].

Overall, these data confirmed an inhibitory effect of pantethine on genes involved in inflammation. Thus, reducing inflammation might in turn abrogate its downstream induced activities including NO production, phagocytosis, and as a consequence the need of neuroprotection. However, we cannot exclude that pantethine acts further upstream by interfering with $A \beta$ production, which, in the long term, will tune down inflammatory processes. Of note, despite the overexpression of inflammatory markers in the 5XFAD mice, no changes were observed in our arrays for the expression of pro-inflammatory genes such as $I l-1 \beta$ or Tnf- $\alpha$. To validate the transcriptional data, RT-qPCR analyses were performed on genes differentially expressed in Tg when compared to WT and the effect of pantethine was evaluated. As shown in Fig. 6A, expression of Gfap, Aifl, and Tlr2 was increased in Tg compared to WT and this increase was significantly reduced by pantethine treatment in Tg but not in WT. Furthermore, although the absence of modulated expression was confirmed for Tnf- $\alpha$ (Fig. 6A), we observed a significantly higher expression of $I l-1 \beta$ in Tg when compared to WT that was decreased by pantethine (Fig. 6B). Such a change in $\mathrm{Il}-1 \beta$ expression was also confirmed at the protein level (Fig. 6C) with a twofold increase in Tg compared to WT, an increase that was completely abrogated by pantethine.

\section{Pantethine Reduces the Expression of Underexpressed Genes in 5XFAD Mice Involved in Neurotransmission and $A \beta$ Production}

For this analysis, we only considered genes filtered for a threshold $\leq 0.6$ in Tg compared to WT animals (Table 2) that were underexpressed in our previous transcriptomic study on hippocampi of either 6- or 9-month-old 5XFAD mice [27]. Decreased expression of Syn2 (synapsin 2) was indeed observed at the earliest clinically detectable stage of AD [73] and significantly downregulated in the hippocampus of the 3xTg-AD mice compared to the WT mice [74]. It encodes a neuron-specific phosphoprotein involved in the regulation of neurotransmitter release and synaptogenesis (Fig. 7) that binds to small synaptic vesicles in the presynaptic nerve terminal [75]. Noteworthy, as pantethine, ginsenoside $\operatorname{Rg} 1$, a drug shown to improve behavioral abnormalities in $\mathrm{AD}$, restores its expression in the hippocampus of 3xTg-AD mice [74].

Reduced Gria2 (glutamate ionotropic receptor AMPA type subunit 2) expression was observed also at 12 months in the hippocampus in 3xTg-AD mice [76]. Its encoded product belongs to a family of glutamate receptors, the main excitatory neurotransmitter at many synapses in the CNS, and functions as ligand-activated cation channels. It was found that Gria2 is subjected to RNA editing, a process shown to be essential for brain function [77], and defective Gria2 editing was observed in the hippocampus of $\mathrm{AD}$ patients [78].

Several other selected genes encoded proteins involved in neurotransmission (Fig. 7). DGKG is a member of the diacylglycerol kinase family belongs to a class of enzymes that catalyze the ATP-dependent conversion of diacylglycerol (DAG1) to phosphatidic acid (PtdOH). It is well documented that the coordinated regulation of these two lipid second messengers is particularly important in the nervous system in which it modulates a variety of neurological functions. Indeed, several reports support roles for these enzymes in neuronal spine density, myelination, synaptic activity, neuronal plasticity, epileptogenesis, and neurotransmitter release (reviewed in [79]). Kcnmal (potassium calcium-activated channel subfamily $\mathrm{M}$ alpha 1 ) encodes the pore-forming alpha subunit of the MaxiK channels that play a role in neuronal excitability [80]. NRXN1 (neurexin 1) is a single-pass type 1 membrane protein that binds neuroligins to form a $\mathrm{Ca}^{2+}$-dependent complex at synapses in the CNS required for neurotransmission [81]. Heterozygous mutations in NRXN1 were found to impair synaptic functions in human neurons [82]. Calcium voltage-gated channels such as CACNA2D1 have an important role in neurotransmission and genomic aberrations of its gene were found in patients with epilepsy and intellectual disability [83].

In addition, pantethine upregulation of several genes suggested a possible inhibitory effect of pantethine on APP processing and $\mathrm{A} \beta$ production (Table 3, Fig. 7), with the exception of Grm5 (metabotropic glutamate receptor 5). Indeed, genetic deletion of this gene inhibits $A \beta$ production of oligomers and amyloid plaques, thus reducing cognitive impairment and pathogenesis in APP/PS1 $\Delta \mathrm{E} 9$, another AD mice model [84]. In contrast, restored expression of Apba2, $A p p b p 2$, and $G p d 2$ should decrease A $\beta$ toxicity. Apba2 (amyloid beta precursor protein family A member 2) encodes a neuronal adapter protein interacting with APP. This interaction stabilizes APP and inhibits production of proteolytic APP fragments including $A \beta$ [85-89]. Furthermore, it was shown that APBA2-mediated reduction in cerebral $\mathrm{A} \beta$ was associated with normalization of both cognition and in vivo long-term potentiation in an $\mathrm{AD}$ transgenic mice model [90]. The protein encoded by Appbp 2 (amyloid beta precursor protein binding protein 2) interacts with microtubules and is functionally associated with APP transport and/or processing [91].

On the other hand, the restored expression of $G p d 2$, glycerol-3-phosphate dehydrogenase 2, can be related to the effect of pantethine on glycolysis because GPD2 is involved in maintaining a high rate of this process [92]. Thus, restoring glycolysis, whose impairment was shown to promote an increase in $A \beta$ aggregation and internalization [93], might be 
Fig. 6 Expression analyses of inflammatory genes. RT-qPCR analyses of inflammatory genes Gfap, Aif1, Csflr, Tlr2, Cyba, and $\operatorname{Tnf}-\alpha(\mathrm{A})$ and Il-1 $\beta(\mathrm{B})$.

Values are the mean \pm SEM of three mice per group normalized to WT. (C) Quantification of IL$1 \beta$ levels in the hippocampus by ELISA. Values are the mean \pm SEM of three mice per group. ${ }^{*} p<0.05$; ** $p<0.01$; $* * * p<0.005$ when comparing $\mathrm{WT}+\mathrm{P}, \mathrm{Tg}$ and $\mathrm{Tg}+\mathrm{P}$ groups vs WT, ANOVA followed by post hoc Fisher LSD test
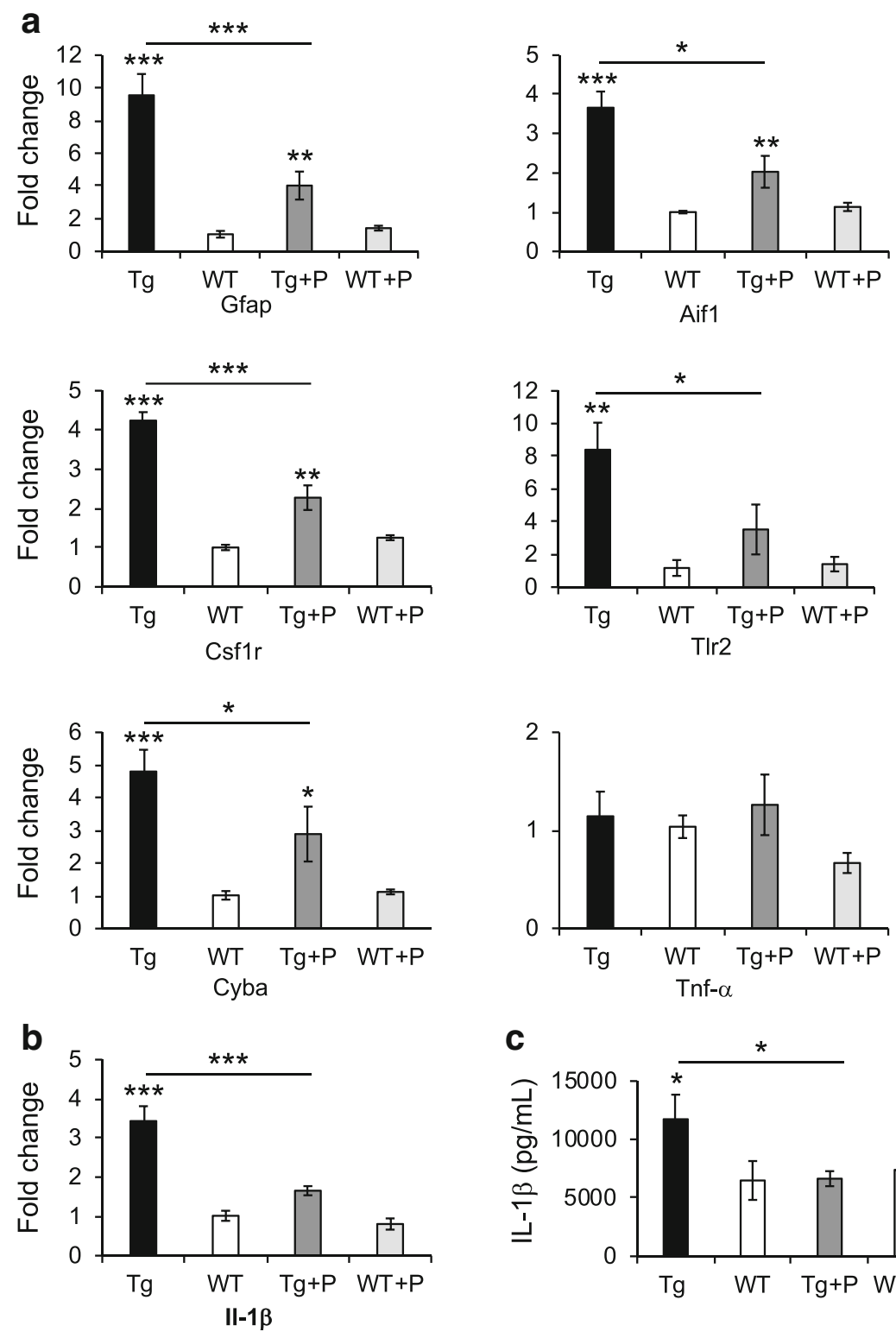

part of the beneficial effect of pantethine. Altogether, these data supported that pantethine maintained the constitutive expression of genes underexpressed in $\mathrm{Tg}$ to preserve proper CNS functions.

\section{Discussion}

Although the clinical impact of pantethine remains to be proven, we presented here some lines of evidence in favor of a beneficial effect of pantethine in AD. Our behavioral test suggested that pantethine treatment reduced aggressiveness (Fig. 2 ). Such an effect was supported by the decrease of astrogliosis and microgliosis as well as a reduction of the number of amyloid plaques (Fig. 1). Although it is well admitted that $\mathrm{AD}$ starts with $\mathrm{A} \beta$ deposition, the precise process that leads to neurodegeneration, is still unknown. $A \beta$ aggregation triggers neuroinflammation that is accompanied with an increase of ROS production resulting in an oxidative stress. Despite the ability of inflammation to increase phagocytosis for $A \beta$ clearance, it is thought that its chronicity can impact negatively the protective activities, and restoration of CNS functions cannot be anymore achieved.

The inhibition of pantethine on $I l-1 \beta$ expression seen in primary cultures of astrocytes upon treatment with $A \beta$ oligomers [17] was confirmed in vivo in the present work at both mRNA and protein levels (Fig. 6B, C). Such a decrease might suggest a direct effect of the drug on the signaling pathway leading to $I l-1 \beta$ expression. For instance, the nuclear factor kappa-light-chain-enhancer of activated B cells $(\mathrm{NF}-\mathrm{kB})$ is one of the factors involved in the transcriptional induction of cytokines such as $I l-1 \beta$ and IL-1 $\beta$-induced inflammatory 

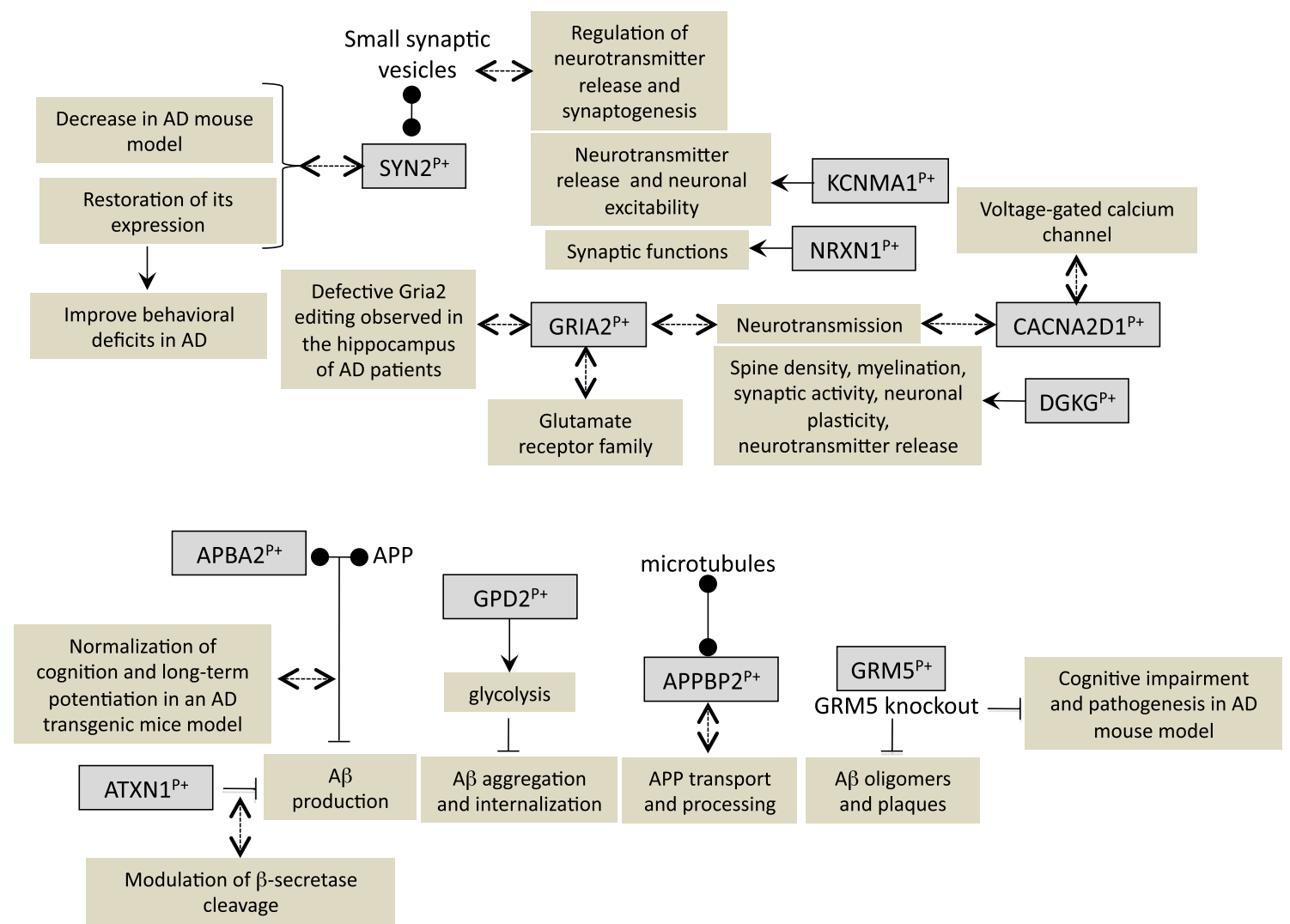

Fig. 7 Schematic representation of functional networks involving genes whose downregulation in Tg was reversed by pantethine. Table of legends is indicated in Fig. 6. Modulated genes are within a gray box and induced expression by pantethine is indicated by $\mathrm{P}+$ in superscript

genes [94]. Reduced activity of NF-KB by blocking IL-1 $\beta$ signaling was described to alleviate cognitive deficits, attenuate Tau pathology, and partly decrease certain fibrillar and oligomeric forms of $A \beta$ [95]. At least part of the mechanism leading to $I l-1 \beta$ expression requires the translocation of

Table 3 Downregulated genes in Tg whose expression was reversed by pantethine. Values represent the ratio of the indicated comparison between groups (three animals per group and normalized to WT). $* p<0.05 ; * * p<0.01$ and $* * * p<0.005$. ANOVA followed by post hoc Fisher LSD test

\begin{tabular}{lllll}
\hline Genes & $\mathrm{Tg} / \mathrm{WT}$ & $\mathrm{Tg}+\mathrm{P} / \mathrm{Tg}$ & $\mathrm{Tg}+\mathrm{P} / \mathrm{WT}$ & $\mathrm{WT}+\mathrm{P} / \mathrm{WT}$ \\
\hline Syn2 & $0.3 * * *$ & $3.1 * * *$ & 0.9 & 0.9 \\
Gria2 & $0.5 * * *$ & $2.1 * *$ & 1 & 1.3 \\
Apba2 & $0.5 *$ & $2 *$ & 1.1 & 1 \\
Appbp2 & $0.5 * * *$ & $1.7 * *$ & $0.7 *$ & 0.8 \\
Grm5 & $0.3 * *$ & $3.7 * *$ & 0.9 & 1 \\
Gpd2 & $0.4 * * *$ & $2.2 * *$ & 0.9 & 0.9 \\
Dgkg & $0.5 * *$ & $1.8 * *$ & 0.9 & 0.9 \\
Kcnma1 & $0.4 * * *$ & $2.1 * *$ & 0.8 & 0.8 \\
Nrxn1 & $0.5 *$ & $2 * *$ & 0.9 & 1 \\
Cacna2d1 & $0.5 *$ & $2.5 * *$ & 1.1 & 1.2 \\
\hline
\end{tabular}

NF- $\mathrm{KB}$ to the nucleus that can be achieved after binding of $\mathrm{A} \beta_{42}$ to TLR2. Although the mechanism of action of pantethine is not yet elucidated, it was shown that pantethine alters lipid composition and cholesterol content of membrane rafts [96]. Such an alteration with methyl- $\beta$-cyclodextrin was reported to decrease the levels of nuclear translocation of NF-KB p65, phosphorylated ERK1/2 and TLR4 [97, 98]. It is therefore possible that through its effects on lipid rafts as prime subcellular regions in which amyloidogenic APP processing takes place [99, 100], pantethine affects NF-KB activation, thus preventing the transcription of inflammatory genes. However, on the one hand, neuroinflammation and IL- $1 \beta$ contribute to neurodegeneration, a hallmark of AD pathology, and on the other hand, IL-1 $\beta$ overexpression in a transgenic $\mathrm{AD}$ model was reported to trigger beneficial effects [101]. Indeed, crossing the APP/PS1 AD mouse model with transgenic mice that specifically overexpress $I l-1 \beta$ (APP/PS1IL-1 $\beta$ ) in the hippocampus led to a reduction of amyloid pathology [101]. It was suggested that reduced amyloid plaques and therefore the beneficial effect of IL-1 $\beta$ resulted from the enhancement of microglial phagocytosis. Recently, mapping the immune cell subsets in AD onset and progression [102] led to the identification of a potential microglia protectivetype associated with neurodegenerative diseases (DAM). 
This subset of cells, which was also detected in post-mortem human brain, is characterized by higher expression levels of genes involved in phagocytic and lipid metabolism pathways. This DAM activation requires a mechanistically coupled temporal event that is initiated in a TREM2-independent pathway, followed by activation of the TREM2-dependent program. As suggested in APP/PS1-IL-1 $\beta$ transgenic mice, a beneficial role of this DAM population was related to its phagocytic activity that should trigger $A \beta$ clearance. However, despite a reduction of plaques, it was shown that neuronal loss induced by low concentration of $\mathrm{A} \beta$ (not leading to neuronal apoptosis) was mediated by primary phagocytosis of neurons by microglia [103]. These observations should provide an explanation for the failure of therapeutic assays based on $A \beta$ vaccination that did not alleviate cognitive deficits [104]. We can hypothesize that pantethine through its anti-inflammatory effect might hamper the phagocytic activity (illustrated by the reduced expression of Tyrobp and Trem2) to a level in which healthy neurons are preserved, although formation of amyloid plaques is reduced.

Although pantethine treatment may be preventive, according to the lipid raft hypothesis, we cannot exclude that it acts only in an AD context. Preliminary results (data not shown) on 4-month-old mice failed to detect any change following pantethine treatment in the expression of genes that were modulated in Tg compared to WT. At this time point, neither Aifl, Gfap, Cd68, Cd14, Lyz, Cyba, Grn, S100a6, Tyrobp, and Trem 2 nor genes encoding complement factors, whose expression was increased in $\mathrm{Tg}$, were affected by pantethine. Moreover, selecting the genes modulated by pantethine in WT did not lead to the identification of processes that can be supported by a significant number of genes.

In addition, another feature that could help understand the beneficial effect of pantethine is related to its role in the production of $\mathrm{CoA}$. Inborn errors of $\mathrm{CoA}$ biosynthesis have been implicated in neurodegeneration with brain iron accumulation (NBIA), a group of rare neurodegenerative disorders, suggesting pantethine as suitable treatment for affected individuals [105]. Moreover, glucose-derived pyruvate is a principal source of acetyl-CoA in all brain cells through pyruvate dehydrogenase complex (PDHC) activity. Pantethine could therefore compensate the decrease of PDHC activity observed in $\mathrm{AD}[106]$ that is responsible for cholinergic deficits and loss of cognitive functions.

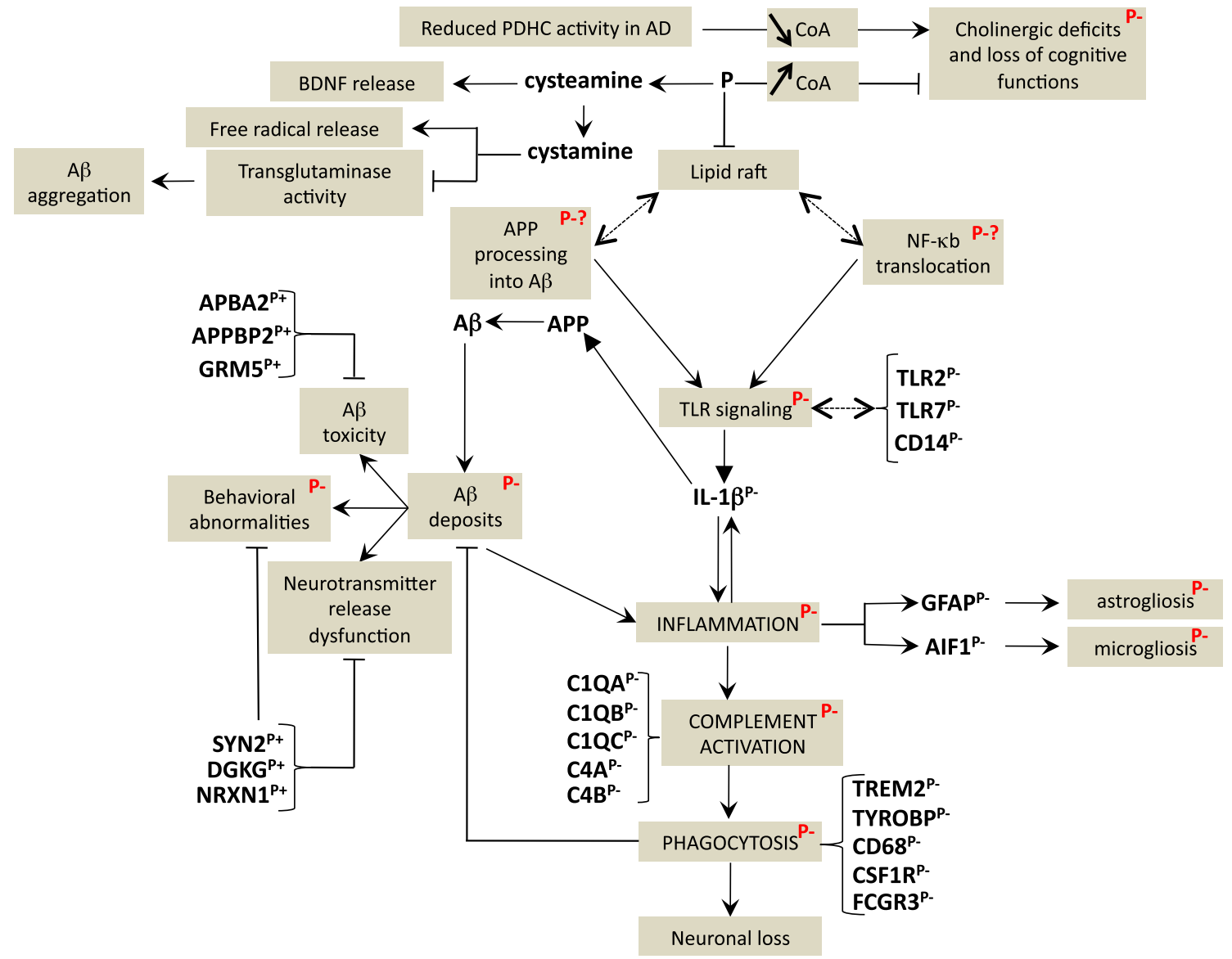

Fig. 8 Schematic representation of pantethine inhibitory activity ( $\mathrm{P}$ in red) in $\mathrm{AD}$ as evidenced in this study. $\mathrm{P}$ followed by a question mark (?) means that the activity remains to be demonstrated. $\mathrm{P}$ with + or - in superscript indicates either an upregulation or a downregulation of the genes in Tg in response to pantethine treatment, respectively, when compared to untreated $\mathrm{Tg}$ 
On the other hand, it is possible that the effects observed in the 5XFAD result from pantethine metabolites. Pantethine can be converted to its monomeric form (pantetheine), which is metabolized by pantetheinase to generate pantothenic acid (vitamin B5) and cysteamine, known to have direct antioxidant effects [107-109]. Cysteamine can cross the bloodbrain barrier [110] and was shown to induce the release of BDNF (brain-derived neurotrophic factor), inhibiting neuronal loss in Huntington's disease [111]. Cysteamine is highly reactive and its oxidation leads to form cystamine. It has been shown that cystamine can activate the activity of NRF2, a crucial transcriptional factor involved in the anti-oxidant response both in cell cultures and in brain tissue [112]. Interestingly, although cystamine inhibits the $\gamma$-glutamyl synthase that consequently blocks ROS scavenging, it reduces transglutaminase activity known to be associated with protein aggregates in $\mathrm{AD}$ brain and to trigger $\mathrm{A} \beta$ oligomerization and aggregation [113]. Noteworthy, no side effects of pantethine were reported $[114,115]$. Thus, in case of clear clinical benefits of pantethine treatment, determining whether pantethine itself or one of its metabolites is responsible should not be a barrier to its use.

\section{Conclusions}

The present study demonstrated the efficiency of pantethine to reverse AD features such as astrogliosis, microgliosis, $\mathrm{A} \beta$ deposition, and to $\mathrm{AD}$-associated aggressive behavior. These changes were accompanied by the reversion of the overexpression of several genes in Tg mice related to inflammation/phagocytosis (summarized in Fig. 8). Because neuroinflammation and phagocytosis are crucial events in the course of $\mathrm{AD}$, the various effects of pantethine or one of its metabolites (cysteamine, cystamine, pantothenic acid) on these processes are of importance. Blocking the signaling pathways that lead to either $A \beta$ deposition, inflammation or oxidative stress or the vicious cycle that amplifies these alterations will have several downstream consequences that altogether can alleviate AD pathology. It will decrease i) APP processing that will in turn reduce $A \beta$ deposition and ii) the NF- $K B$ signaling pathway involved in the transcriptional activation of inflammatory genes and in particular those involved in phagocytosis such as TREM2. Ultimately, the reduced expression of these genes will impact the generation of the highly phagocytic DAM population and consequently might protect healthy neurons from phagocytosis and therefore neuronal loss.

Investigating more deeply the mechanism that sustain the effects of pantethine in 5XFAD mice overtime should determine whether pantethine treatment is preventive or curative. In addition to test depicting mood changes (i.e., aggressiveness), cognitive evaluations will have to be performed in order to provide further confirmation of the beneficial therapeutic effect of pantethine treatment. Based on our results, pantethine, provided routinely as a dietary supplement, could be considered as a serious therapeutic option for preventing, slowing, or halting $\mathrm{AD}$ progression.

Acknowledgements The authors thank Dr. Véréna Landel for critical reading of the manuscript and Dr. Marek Gierlinski for his help with statistical analysis.

Required Author Forms Disclosure forms provided by the authors are available with the online version of this article.

Author Contributions KB, MvGB, DS, SR, MK, BG, MdR, and PB performed experiments, collected, analyzed, and interpreted data. WC performed the microarray experiment. $\mathrm{KB}, \mathrm{BG}, \mathrm{MdR}$, and $\mathrm{PB}$ wrote the manuscript. MdR and $\mathrm{PB}$ supervised the project.

Funding This work was supported by funding from CNRS and AixMarseille Université; Agence Nationale pour la Recherche (MK, \#ANR-11-MALZ-0007 and SR, \#ANR-15-CE16-0006); Fonds Européens de Développement Régional (FEDER in PACA, MK and SR, \#3013-33278); DHUNE project supported by A*MIDEX (MK and SR, \#ANR-11-IDEX-0001-02) and Vaincre l'Alzheimer (MK, \#13745). KB was granted a research associate fellowship (Management of Talents) by A*MIDEX and the "Fondation Plan Alzheimer". MvGB was recipient of a private doctoral fellowship.

Data Availability The microarray datasets generated in the present study are available in the Array Express database [www.ebi.ac.uk/arrayexpress] under accession number E-MTAB-6772.

\section{Compliance with Ethical Standards}

Conflict of Interest The authors declare that they have conflict of interest.

Ethics Approval and Consent to Participate All experimental procedures were approved by the Ethics Committee of the Medical Faculty of Marseille and were carried out in accordance with the guidelines published in the European Communities Council Directive of November 24, 1986 (86/609/EEC). All efforts were made to reduce animal suffering and the number of mice.

\section{References}

1. Selkoe DJ, Hardy J. The amyloid hypothesis of Alzheimer's disease at 25 years. EMBO molecular medicine. 2016 Jun;8(6):595-608.

2. Tuppo EE, Arias HR. The role of inflammation in Alzheimer's disease. The international journal of biochemistry \& cell biology. 2005 Feb;37(2):289-305.

3. Ardura-Fabregat A, Boddeke E, Boza-Serrano A, Brioschi S, Castro-Gomez S, Ceyzeriat K, et al. Targeting Neuroinflammation to Treat Alzheimer's Disease. CNS drugs. 2017 Dec;31(12):1057-82.

4. Stewart WF, Kawas C, Corrada M, Metter EJ. Risk of Alzheimer's disease and duration of NSAID use. Neurology. 1997 Mar;48(3): 626-32. 
5. Etminan M, Gill S, Samii A. Effect of non-steroidal anti-inflammatory drugs on risk of Alzheimer's disease: systematic review and meta-analysis of observational studies. Bmj. 2003 Jul 19;327(7407):128.

6. Soininen $\mathrm{H}$, West C, Robbins J, Niculescu L. Long-term efficacy and safety of celecoxib in Alzheimer's disease. Dementia and geriatric cognitive disorders. 2007;23(1):8-21.

7. Group A-FR. Follow-up evaluation of cognitive function in the randomized Alzheimer's Disease Anti-inflammatory Prevention Trial and its Follow-up Study. Alzheimer's \& dementia : the journal of the Alzheimer's Association. 2015 Feb;11(2):216-25 e1.

8. Wyss-Coray T. Inflammation in Alzheimer disease: driving force, bystander or beneficial response? Nature medicine. 2006 Sep;12(9):1005-15.

9. Chen YQ, Zhao SP, Zhao YH. Efficacy and tolerability of coenzyme A vs pantethine for the treatment of patients with hyperlipidemia: A randomized, double-blind, multicenter study. Journal of clinical lipidology. 2015 Sep-Oct;9(5):692-7.

10. Vecsei L, Widerlov E, Alling C. Effects of pantethine, cysteamine and pantothenic acid on open-field behavior and brain catecholamines in rats. Archives internationales de pharmacodynamie et de therapie. 1989 Jul-Aug;300:14-21.

11. Kaskow BJ, Proffitt JM, Blangero J, Moses EK, Abraham LJ. Diverse biological activities of the vascular non-inflammatory molecules - the Vanin pantetheinases. Biochemical and biophysical research communications. 2012 Jan 13;417(2):653-8.

12. Brunetti D, Dusi S, Giordano C, Lamperti C, Morbin M, Fugnanesi $\mathrm{V}$, et al. Pantethine treatment is effective in recovering the disease phenotype induced by ketogenic diet in a pantothenate kinase-associated neurodegeneration mouse model. Brain : a journal of neurology. $2014 \mathrm{Jan} ; 137(\mathrm{Pt}$ 1):57-68.

13. Cornille E, Abou-Hamdan M, Khrestchatisky M, Nieoullon A, de Reggi M, Gharib B. Enhancement of L-3-hydroxybutyryl-CoA dehydrogenase activity and circulating ketone body levels by pantethine. Relevance to dopaminergic injury. BMC neuroscience. 2010 Apr 23;11:51.

14. Rana A, Seinen E, Siudeja K, Muntendam R, Srinivasan B, van der Want JJ, et al. Pantethine rescues a Drosophila model for pantothenate kinase-associated neurodegeneration. Proceedings of the National Academy of Sciences of the United States of America. 2010 Apr 13;107(15):6988-93.

15. Kavian N, Marut W, Servettaz A, Nicco C, Chereau C, Lemarechal H, et al. Pantethine Prevents Murine Systemic Sclerosis Through the Inhibition of Microparticle Shedding. Arthritis \& rheumatology. 2015 Jul;67(7):1881-90.

16. Penet MF, Abou-Hamdan M, Coltel N, Cornille E, Grau GE, de Reggi M, et al. Protection against cerebral malaria by the lowmolecular-weight thiol pantethine. Proceedings of the National Academy of Sciences of the United States of America. 2008 Jan 29;105(4):1321-6.

17. van Gijsel-Bonnello M, Baranger K, Benech P, Rivera S, Khrestchatisky M, de Reggi M, et al. Metabolic changes and inflammation in cultured astrocytes from the $5 \mathrm{xFAD}$ mouse model of Alzheimer's disease: Alleviation by pantethine. PloS one. 2017;12(4):e0175369.

18. Oakley H, Cole SL, Logan S, Maus E, Shao P, Craft J, et al. Intraneuronal beta-amyloid aggregates, neurodegeneration, and neuron loss in transgenic mice with five familial Alzheimer's disease mutations: potential factors in amyloid plaque formation. The Journal of neuroscience : the official journal of the Society for Neuroscience. 2006 Oct 4;26(40):10129-40.

19. Py NA, Bonnet AE, Bernard A, Marchalant Y, Charrat E, Checler F, et al. Differential spatio-temporal regulation of MMPs in the $5 x F A D$ mouse model of Alzheimer's disease: evidence for a proamyloidogenic role of MT1-MMP. Frontiers in aging neuroscience. 2014;6:247.
20. Kimura R, Ohno M. Impairments in remote memory stabilization precede hippocampal synaptic and cognitive failures in 5XFAD Alzheimer mouse model. Neurobiology of disease. 2009 Feb;33(2):229-35.

21. Crouzin N, Baranger K, Cavalier M, Marchalant Y, Cohen-Solal $\mathrm{C}$, Roman FS, et al. Area-specific alterations of synaptic plasticity in the 5XFAD mouse model of Alzheimer's disease: dissociation between somatosensory cortex and hippocampus. PloS one. 2013;8(9):e74667.

22. Girard SD, Baranger K, Gauthier C, Jacquet M, Bernard A, Escoffier G, et al. Evidence for early cognitive impairment related to frontal cortex in the 5XFAD mouse model of Alzheimer's disease. Journal of Alzheimer's disease: JAD. 2013;33(3):781-96.

23. Girard SD, Jacquet M, Baranger K, Migliorati M, Escoffier G, Bernard A, et al. Onset of hippocampus-dependent memory impairments in 5XFAD transgenic mouse model of Alzheimer's disease. Hippocampus. 2014 Jul;24(7):762-72.

24. Baranger K, Marchalant Y, Bonnet AE, Crouzin N, Carrete A, Paumier JM, et al. MT5-MMP is a new pro-amyloidogenic proteinase that promotes amyloid pathology and cognitive decline in a transgenic mouse model of Alzheimer's disease. Cellular and molecular life sciences : CMLS. 2016 Jan;73(1):217-36.

25. Baranger K, Giannoni P, Girard SD, Girot S, Gaven F, Stephan D, et al. Chronic treatments with a 5-HT4 receptor agonist decrease amyloid pathology in the entorhinal cortex and learning and memory deficits in the 5xFAD mouse model of Alzheimer's disease. Neuropharmacology. 2017 Nov;126:128-41.

26. Eimer WA, Vassar R. Neuron loss in the 5XFAD mouse model of Alzheimer's disease correlates with intraneuronal Abeta42 accumulation and Caspase-3 activation. Molecular neurodegeneration. 2013 Jan 14;8:2.

27. Landel V, Baranger K, Virard I, Loriod B, Khrestchatisky M, Rivera S, et al. Temporal gene profiling of the 5XFAD transgenic mouse model highlights the importance of microglial activation in Alzheimer's disease. Molecular neurodegeneration. 2014 Sep 11;9:33.

28. Landel V, Millet P, Baranger K, Loriod B, Feron F. Vitamin D interacts with Esrl and Igfl to regulate molecular pathways relevant to Alzheimer's disease. Molecular neurodegeneration. 2016 Mar 1;11:22.

29. Saeed AI, Sharov V, White J, Li J, Liang W, Bhagabati N, et al. TM4: a free, open-source system for microarray data management and analysis. BioTechniques. 2003 Feb;34(2):374-8.

30. Baranger K, Bonnet AE, Girard SD, Paumier JM, GarciaGonzalez L, Elmanaa W, et al. MT5-MMP Promotes Alzheimer's Pathogenesis in the Frontal Cortex of 5xFAD Mice and APP Trafficking in vitro. Frontiers in molecular neuroscience. 2017;9:163.

31. Koolhaas JM, Schuurman T, Wiepkema PR. The organization of intraspecific agonistic behaviour in the rat. Progress in neurobiology. 1980;15(3):247-68.

32. Schneider F, Baldauf K, Wetzel W, Reymann KG. Behavioral and EEG changes in male 5xFAD mice. Physiology \& behavior. 2014 Aug; 135:25-33.

33. Bidzan L, Bidzan M, Pachalska M. Aggressive and impulsive behavior in Alzheimer's disease and progression of dementia. Medical science monitor : international medical journal of experimental and clinical research. 2012 Mar;18(3):CR182-9.

34. Rouch I, Dorey JM, Boublay N, Henaff MA, Dibie-Racoupeau F, Makaroff Z, et al. Personality, Alzheimer's disease and behavioural and cognitive symptoms of dementia: the PACO prospective cohort study protocol. BMC geriatrics. 2014 Oct 10;14:110.

35. Ballard C, Corbett A. Agitation and aggression in people with Alzheimer's disease. Current opinion in psychiatry. 2013 May;26(3):252-9. 
36. Pugh PL, Richardson JC, Bate ST, Upton N, Sunter D. Noncognitive behaviours in an APP/PS1 transgenic model of Alzheimer's disease. Behavioural brain research. 2007 Mar 12;178(1):18-28.

37. Vloeberghs E, Van Dam D, Coen K, Staufenbiel M, De Deyn PP. Aggressive male APP23 mice modeling behavioral alterations in dementia. Behavioral neuroscience. 2006 Dec;120(6):1380-3.

38. Yan L, Li L, Han W, Pan B, Xue X, Mei B. Age-related neuropsychiatric symptoms in presenilins conditional double knockout mice. Brain research bulletin. 2013 Aug;97:104-11.

39. Molino Y, Jabes F, Bonnet A, Gaudin N, Bernard A, Benech P, et al. Gene expression comparison reveals distinct basal expression of HOX members and differential TNF-induced response between brain- and spinal cord-derived microvascular endothelial cells. Journal of neuroinflammation. 2016 Nov 10;13(1):290.

40. Yin Z, Raj D, Saiepour N, Van Dam D, Brouwer N, Holtman IR, et al. Immune hyperreactivity of Abeta plaque-associated microglia in Alzheimer's disease. Neurobiology of aging. 2017 Jul;55:115-22.

41. Boom A, Pochet R, Authelet M, Pradier L, Borghgraef P, Van Leuven F, et al. Astrocytic calcium/zinc binding protein S100A6 over expression in Alzheimer's disease and in PS1/APP transgenic mice models. Biochimica et biophysica acta. 2004 Dec 6;1742(13):161-8.

42. Letiembre M, Liu Y, Walter S, Hao W, Pfander T, Wrede A, et al. Screening of innate immune receptors in neurodegenerative diseases: a similar pattern. Neurobiology of aging. 2009 May;30(5): 759-68.

43. Landreth GE, Reed-Geaghan EG. Toll-like receptors in Alzheimer's disease. Current topics in microbiology and immunology. 2009;336:137-53.

44. Hoffmann O, Braun JS, Becker D, Halle A, Freyer D, Dagand E, et al. TLR2 mediates neuroinflammation and neuronal damage. Journal of immunology. 2007 May 15;178(10):6476-81.

45. Liu S, Liu Y, Hao W, Wolf L, Kiliaan AJ, Penke B, et al. TLR2 is a primary receptor for Alzheimer's amyloid beta peptide to trigger neuroinflammatory activation. Journal of immunology. 2012 Feb 1;188(3):1098-107.

46. Reed-Geaghan EG, Reed QW, Cramer PE, Landreth GE. Deletion of CD14 attenuates Alzheimer's disease pathology by influencing the brain's inflammatory milieu. The Journal of neuroscience : the official journal of the Society for Neuroscience. 2010 Nov 17;30(46):15369-73.

47. Yasojima K, Schwab C, McGeer EG, McGeer PL. Up-regulated production and activation of the complement system in Alzheimer's disease brain. The American journal of pathology. 1999 Mar;154(3):927-36.

48. Kolev MV, Ruseva MM, Harris CL, Morgan BP, Donev RM. Implication of complement system and its regulators in Alzheimer's disease. Current neuropharmacology. 2009 Mar;7(1):1-8.

49. Akiyama H, Barger S, Barnum S, Bradt B, Bauer J, Cole GM, et al. Inflammation and Alzheimer's disease. Neurobiology of aging. 2000 May-Jun;21(3):383-421.

50. Bradt BM, Kolb WP, Cooper NR. Complement-dependent proinflammatory properties of the Alzheimer's disease beta-peptide. The Journal of experimental medicine. 1998 Aug 03;188(3): 431-8.

51. Gasque P, Fontaine M, Morgan BP. Complement expression in human brain. Biosynthesis of terminal pathway components and regulators in human glial cells and cell lines. Journal of immunology. 1995 May 1;154(9):4726-33.

52. Morgan BP, Gasque P. Extrahepatic complement biosynthesis: where, when and why? Clinical and experimental immunology. 1997 Jan;107(1):1-7.

53. Pisalyaput K, Tenner AJ. Complement component $\mathrm{C} 1 \mathrm{q}$ inhibits beta-amyloid- and serum amyloid P-induced neurotoxicity via caspase- and calpain-independent mechanisms. Journal of neurochemistry. 2008 Feb;104(3):696-707.

54. Maier M, Peng Y, Jiang L, Seabrook TJ, Carroll MC, Lemere CA. Complement $\mathrm{C} 3$ deficiency leads to accelerated amyloid beta plaque deposition and neurodegeneration and modulation of the microglia/macrophage phenotype in amyloid precursor protein transgenic mice. The Journal of neuroscience : the official journal of the Society for Neuroscience. 2008 Jun 18;28(25):6333-41.

55. Liu Y, Walter S, Stagi M, Cherny D, Letiembre M, SchulzSchaeffer W, et al. LPS receptor (CD14): a receptor for phagocytosis of Alzheimer's amyloid peptide. Brain : a journal of neurology. 2005 Aug;128(Pt 8):1778-89.

56. Smith AM, Gibbons HM, Oldfield RL, Bergin PM, Mee EW, Curtis MA, et al. M-CSF increases proliferation and phagocytosis while modulating receptor and transcription factor expression in adult human microglia. Journal of neuroinflammation. 2013 Jul 17;10:85.

57. Sosna J, Philipp S, Albay R, 3rd, Reyes-Ruiz JM, BagliettoVargas D, LaFerla FM, et al. Early long-term administration of the CSF1R inhibitor PLX3397 ablates microglia and reduces accumulation of intraneuronal amyloid, neuritic plaque deposition and pre-fibrillar oligomers in 5XFAD mouse model of Alzheimer's disease. Molecular neurodegeneration. 2018 Mar 1;13(1):11.

58. Lue LF, Schmitz C, Walker DG. What happens to microglial TREM2 in Alzheimer's disease: Immunoregulatory turned into immunopathogenic? Neuroscience. 2015 Aug 27;302:138-50.

59. Painter MM, Atagi Y, Liu CC, Rademakers R, Xu H, Fryer JD, et al. TREM2 in CNS homeostasis and neurodegenerative disease. Molecular neurodegeneration. 2015 Sep 4;10:43.

60. Jay TR, Miller CM, Cheng PJ, Graham LC, Bemiller S, Broihier ML, et al. TREM2 deficiency eliminates TREM2+ inflammatory macrophages and ameliorates pathology in Alzheimer's disease mouse models. The Journal of experimental medicine. 2015 Mar 9;212(3):287-95.

61. Autieri MV, Kelemen SE, Wendt KW. AIF-1 is an actinpolymerizing and Rac1-activating protein that promotes vascular smooth muscle cell migration. Circulation research. 2003 May 30;92(10):1107-14.

62. Utomo A, Cullere X, Glogauer M, Swat W, Mayadas TN. Vav proteins in neutrophils are required for FcgammaR-mediated signaling to Rac GTPases and nicotinamide adenine dinucleotide phosphate oxidase component p40(phox). Journal of immunology. 2006 Nov 01;177(9):6388-97.

63. Shimohama S, Tanino H, Kawakami N, Okamura N, Kodama H, Yamaguchi T, et al. Activation of NADPH oxidase in Alzheimer's disease brains. Biochemical and biophysical research communications. 2000 Jun 24;273(1):5-9.

64. Niedergang F, Chavrier P. Signaling and membrane dynamics during phagocytosis: many roads lead to the phagos(R)ome. Current opinion in cell biology. 2004 Aug;16(4):422-8.

65. Hickman SE, Kingery ND, Ohsumi TK, Borowsky ML, Wang LC, Means TK, et al. The microglial sensome revealed by direct RNA sequencing. Nature neuroscience. 2013 Dec;16(12):1896-905.

66. Kyrkanides S, Yang M, Tallents RH, Miller JN, Brouxhon SM, Olschowka JA. The trigeminal retrograde transfer pathway in the treatment of neurodegeneration. Journal of neuroimmunology. 2009 Apr 30;209(1-2):139-42.

67. Ghidoni R, Paterlini A, Benussi L. Circulating progranulin as a biomarker for neurodegenerative diseases. American journal of neurodegenerative disease. 2012;1(2):180-90.

68. Masliah E, Ho G, Wyss-Coray T. Functional role of TGF beta in Alzheimer's disease microvascular injury: lessons from transgenic mice. Neurochemistry international. 2001 Nov-Dec;39(5-6):393400 . 
69. Kasten-Jolly J, Heo Y, Lawrence DA. Central nervous system cytokine gene expression: modulation by lead. Journal of biochemical and molecular toxicology. $2011 \mathrm{Jan}-\mathrm{Feb} ; 25(1): 41-54$.

70. Caraci F, Spampinato S, Sortino MA, Bosco P, Battaglia G, Bruno $\mathrm{V}$, et al. Dysfunction of TGF-betal signaling in Alzheimer's disease: perspectives for neuroprotection. Cell and tissue research. 2012 Jan;347(1):291-301.

71. Huang WC, Yen FC, Shie FS, Pan CM, Shiao YJ, Yang CN, et al. TGF-beta1 blockade of microglial chemotaxis toward Abeta aggregates involves SMAD signaling and down-regulation of CCL5. Journal of neuroinflammation. 2010 Apr 29;7:28.

72. Tesseur I, Zou K, Esposito L, Bard F, Berber E, Can JV, et al. Deficiency in neuronal TGF-beta signaling promotes neurodegeneration and Alzheimer's pathology. The Journal of clinical investigation. 2006 Nov;116(11):3060-9.

73. Ho L, Guo Y, Spielman L, Petrescu O, Haroutunian V, Purohit D, et al. Altered expression of a-type but not b-type synapsin isoform in the brain of patients at high risk for Alzheimer's disease assessed by DNA microarray technique. Neuroscience letters. 2001 Feb 09;298(3):191-4.

74. Nie L, Xia J, Li H, Zhang Z, Yang Y, Huang X, et al. Ginsenoside Rg1 Ameliorates Behavioral Abnormalities and Modulates the Hippocampal Proteomic Change in Triple Transgenic Mice of Alzheimer's Disease. Oxidative medicine and cellular longevity. 2017;2017:6473506.

75. Wang L, Das U, Scott DA, Tang Y, McLean PJ, Roy S. alphasynuclein multimers cluster synaptic vesicles and attenuate recycling. Current biology : CB. 2014 Oct 06;24(19):2319-26.

76. Saura CA, Parra-Damas A, Enriquez-Barreto L. Gene expression parallels synaptic excitability and plasticity changes in Alzheimer's disease. Frontiers in cellular neuroscience. 2015;9:318.

77. Satterlee JS, Basanta-Sanchez M, Blanco S, Li JB, Meyer K, Pollock J, et al. Novel RNA modifications in the nervous system: form and function. The Journal of neuroscience : the official journal of the Society for Neuroscience. 2014 Nov 12;34(46):15170-7.

78. Gaisler-Salomon I, Kravitz E, Feiler Y, Safran M, Biegon A, Amariglio N, et al. Hippocampus-specific deficiency in RNA editing of GluA2 in Alzheimer's disease. Neurobiology of aging. 2014 Aug;35(8):1785-91.

79. Tu-Sekine B, Raben DM. Regulation and roles of neuronal diacylglycerol kinases: a lipid perspective. Critical reviews in biochemistry and molecular biology. 2011 Oct;46(5):353-64.

80. Hu H, Shao LR, Chavoshy S, Gu N, Trieb M, Behrens R, et al. Presynaptic $\mathrm{Ca} 2+-$ activated $\mathrm{K}+$ channels in glutamatergic hippocampal terminals and their role in spike repolarization and regulation of transmitter release. The Journal of neuroscience : the official journal of the Society for Neuroscience. 2001 Dec 15;21(24): 9585-97.

81. Paatero A, Rosti K, Shkumatov AV, Sele C, Brunello C, Kysenius K, et al. Crystal Structure of an Engineered LRRTM2 Synaptic Adhesion Molecule and a Model for Neurexin Binding. Biochemistry. 2016 Feb 16;55(6):914-26.

82. Pak C, Danko T, Zhang Y, Aoto J, Anderson G, Maxeiner S, et al. Human Neuropsychiatric Disease Modeling using Conditional Deletion Reveals Synaptic Transmission Defects Caused by Heterozygous Mutations in NRXN1. Cell stem cell. 2015 Sep 03;17(3):316-28.

83. Vergult S, Dheedene A, Meurs A, Faes F, Isidor B, Janssens S, et al. Genomic aberrations of the CACNA2D1 gene in three patients with epilepsy and intellectual disability. European journal of human genetics : EJHG. 2015 May;23(5):628-32.

84. Hamilton A, Esseltine JL, DeVries RA, Cregan SP, Ferguson SS. Metabotropic glutamate receptor 5 knockout reduces cognitive impairment and pathogenesis in a mouse model of Alzheimer's disease. Molecular brain. 2014 May 29;7:40.
85. Sakuma M, Tanaka E, Taru H, Tomita S, Gandy S, Nairn AC, et al. Phosphorylation of the amino-terminal region of X11L regulates its interaction with APP. Journal of neurochemistry. 2009 Apr;109(2):465-75.

86. Swistowski A, Zhang Q, Orcholski ME, Crippen D, Vitelli C, Kurakin A, et al. Novel mediators of amyloid precursor protein signaling. The Journal of neuroscience : the official journal of the Society for Neuroscience. 2009 Dec 16;29(50):15703-12.

87. Tomita S, Ozaki T, Taru H, Oguchi S, Takeda S, Yagi Y, et al. Interaction of a neuron-specific protein containing PDZ domains with Alzheimer's amyloid precursor protein. The Journal of biological chemistry. 1999 Jan 22;274(4):2243-54.

88. Lee JH, Lau KF, Perkinton MS, Standen CL, Rogelj B, Falinska A, et al. The neuronal adaptor protein X11beta reduces amyloid beta-protein levels and amyloid plaque formation in the brains of transgenic mice. The Journal of biological chemistry. 2004 Nov 19;279(47):49099-104.

89. Araki Y, Tomita S, Yamaguchi H, Miyagi N, Sumioka A, Kirino Y, et al. Novel cadherin-related membrane proteins, Alcadeins, enhance the X11-like protein-mediated stabilization of amyloid beta-protein precursor metabolism. The Journal of biological chemistry. 2003 Dec 5;278(49):49448-58.

90. Mitchell JC, Ariff BB, Yates DM, Lau KF, Perkinton MS, Rogelj $\mathrm{B}$, et al. X11beta rescues memory and long-term potentiation deficits in Alzheimer's disease APPswe Tg2576 mice. Human molecular genetics. 2009 Dec 01;18(23):4492-500.

91. Dilsizoglu Senol A, Tagliafierro L, Huguet L, Gorisse-Hussonnois L, Chasseigneaux S, Allinquant B. PAT1 inversely regulates the surface Amyloid Precursor Protein level in mouse primary neurons. BMC neuroscience. 2015 Mar 07;16:10.

92. Chowdhury SK, Gemin A, Singh G. High activity of mitochondrial glycerophosphate dehydrogenase and glycerophosphatedependent ROS production in prostate cancer cell lines. Biochemical and biophysical research communications. 2005 Aug 12;333(4):1139-45.

93. Fu W, Shi D, Westaway D, Jhamandas JH. Bioenergetic mechanisms in astrocytes may contribute to amyloid plaque deposition and toxicity. The Journal of biological chemistry. 2015 May 15;290(20):12504-13.

94. Warner N, Nunez G. MyD88: a critical adaptor protein in innate immunity signal transduction. Journal of immunology. 2013 Jan 1;190(1):3-4.

95. Kitazawa M, Cheng D, Tsukamoto MR, Koike MA, Wes PD, Vasilevko V, et al. Blocking IL-1 signaling rescues cognition, attenuates tau pathology, and restores neuronal beta-catenin pathway function in an Alzheimer's disease model. Journal of immunology. 2011 Dec 15;187(12):6539-49.

96. van Gijsel-Bonnello M, Acar N, Molino Y, Bretillon L, Khrestchatisky M, de Reggi M, et al. Pantethine Alters Lipid Composition and Cholesterol Content of Membrane Rafts, With Down-Regulation of CXCL12-Induced T Cell Migration. J Cell Physiol. 2015 Feb 27.

97. Pan Y, Sun X, Jiang L, Hu L, Kong H, Han Y, et al. Metformin reduces morphine tolerance by inhibiting microglial-mediated neuroinflammation. Journal of neuroinflammation. 2016 Nov 17;13(1):294.

98. Pan Y, Liu B, Deng Z, Fan Y, Li J, Li H. Lipid Rafts Promote trans Fatty Acid-Induced Inflammation in Human Umbilical Vein Endothelial Cells. Lipids. 2017 Jan;52(1):27-35.

99. Schengrund CL. Lipid rafts: keys to neurodegeneration. Brain research bulletin. 2010 Apr 29;82(1-2):7-17.

100. Hicks DA, Nalivaeva NN, Turner AJ. Lipid rafts and Alzheimer's disease: protein-lipid interactions and perturbation of signaling. Frontiers in physiology. 2012;3:189.

101. Shaftel SS, Kyrkanides S, Olschowka JA, Miller JN, Johnson RE, O'Banion MK. Sustained hippocampal IL-1 beta overexpression 
mediates chronic neuroinflammation and ameliorates Alzheimer plaque pathology. The Journal of clinical investigation. 2007 Jun;117(6):1595-604.

102. Keren-Shaul H, Spinrad A, Weiner A, Matcovitch-Natan O, DvirSzternfeld R, Ulland TK, et al. A Unique Microglia Type Associated with Restricting Development of Alzheimer's Disease. Cell. 2017 Jun 15;169(7):1276-90 e17.

103. Neniskyte U, Neher JJ, Brown GC. Neuronal death induced by nanomolar amyloid beta is mediated by primary phagocytosis of neurons by microglia. The Journal of biological chemistry. 2011 Nov 18;286(46):39904-13.

104. Gilman S, Koller M, Black RS, Jenkins L, Griffith SG, Fox NC, et al. Clinical effects of Abeta immunization (AN1792) in patients with AD in an interrupted trial. Neurology. 2005 May 10;64(9): 1553-62.

105. Iuso A, Wiersma M, Schuller HJ, Pode-Shakked B, Marek-Yagel $\mathrm{D}$, Grigat M, et al. Mutations in PPCS, Encoding Phosphopantothenoylcysteine Synthetase, Cause AutosomalRecessive Dilated Cardiomyopathy. American journal of human genetics. 2018 Jun 7;102(6):1018-30.

106. Sorbi S, Bird ED, Blass JP. Decreased pyruvate dehydrogenase complex activity in Huntington and Alzheimer brain. Annals of neurology. 1983 Jan;13(1):72-8.

107. Aruoma OI, Halliwell B, Hoey BM, Butler J. The antioxidant action of taurine, hypotaurine and their metabolic precursors. The Biochemical journal. 1988 Nov 15;256(1):251-5.

108. Jeitner TM, Delikatny EJ, Ahlqvist J, Capper H, Cooper AJ. Mechanism for the inhibition of transglutaminase 2 by cystamine. Biochemical pharmacology. 2005 Mar 15;69(6):961-70.

109. Martin F, Penet MF, Malergue F, Lepidi H, Dessein A, Galland F, et al. Vanin-1(-/-) mice show decreased NSAID- and Schistosoma-induced intestinal inflammation associated with higher glutathione stores. The Journal of clinical investigation. 2004 Feb;113(4):591-7.
110. Bousquet M, Gibrat C, Ouellet M, Rouillard C, Calon F, Cicchetti F. Cystamine metabolism and brain transport properties: clinical implications for neurodegenerative diseases. Journal of neurochemistry. 2010 Sep;114(6):1651-8.

111. Borrell-Pages M, Canals JM, Cordelieres FP, Parker JA, Pineda JR, Grange G, et al. Cystamine and cysteamine increase brain levels of BDNF in Huntington disease via HSJ1b and transglutaminase. The Journal of clinical investigation. 2006 May;116(5):1410-24.

112. Calkins MJ, Townsend JA, Johnson DA, Johnson JA. Cystamine protects from 3-nitropropionic acid lesioning via induction of nfe2 related factor 2 mediated transcription. Experimental neurology. $2010 \mathrm{Jul} ; 224(1): 307-17$.

113. Martin A, De Vivo G, Gentile V. Possible role of the transglutaminases in the pathogenesis of Alzheimer's disease and other neurodegenerative diseases. International journal of Alzheimer's disease. 2011 Feb 16;2011:865432.

114. Coronel F, Tornero F, Torrente J, Naranjo P, De Oleo P, Macia M, et al. Treatment of hyperlipemia in diabetic patients on dialysis with a physiological substance. American journal of nephrology. 1991;11(1):32-6.

115. Evans M, Rumberger JA, Azumano I, Napolitano JJ, Citrolo D, Kamiya T. Pantethine, a derivative of vitamin B5, favorably alters total, LDL and non-HDL cholesterol in low to moderate cardiovascular risk subjects eligible for statin therapy: a triple-blinded placebo and diet-controlled investigation. Vascular health and risk management. 2014;10:89-100.

Publisher's Note Springer Nature remains neutral with regard to jurisdictional claims in published maps and institutional affiliations. 